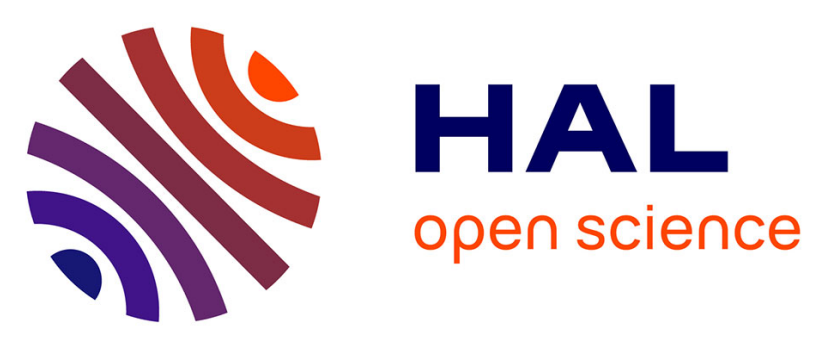

\title{
Changes in SK channel expression in the basal ganglia after partial nigrostriatal dopamine lesions in rats: Functional consequences
}

Christiane Mourre, Christine Manrique, Jeremy Camon, Sabrine Aidi-Knani, Thierry Deltheil, Nathalie Turle-Lorenzo, Gaelle Guiraudie-Capraz, Marianne Amalric

\section{To cite this version:}

Christiane Mourre, Christine Manrique, Jeremy Camon, Sabrine Aidi-Knani, Thierry Deltheil, et al.. Changes in SK channel expression in the basal ganglia after partial nigrostriatal dopamine lesions in rats: Functional consequences. Neuropharmacology, 2017, 113, Part A, pp.519-532. 10.1016/j.neuropharm.2016.11.003 . hal-01470385

\section{HAL Id: hal-01470385 https://hal.science/hal-01470385}

Submitted on 28 Nov 2019

HAL is a multi-disciplinary open access archive for the deposit and dissemination of scientific research documents, whether they are published or not. The documents may come from teaching and research institutions in France or abroad, or from public or private research centers.
L'archive ouverte pluridisciplinaire HAL, est destinée au dépôt et à la diffusion de documents scientifiques de niveau recherche, publiés ou non, émanant des établissements d'enseignement et de recherche français ou étrangers, des laboratoires publics ou privés. 


\section{Accepted Manuscript}

Changes in SK channel expression in the basal ganglia after partial nigrostriatal dopamine lesions in rats: Functional consequences

Christiane Mourre, Christine Manrique, Jeremy Camon, Sabrine Aidi-Knani, Thierry Deltheil, Nathalie Turle-Lorenzo, Gaelle Guiraudie-Capraz, Marianne Amalric

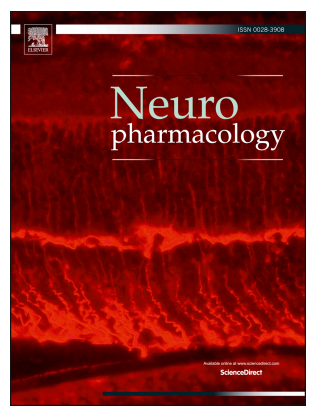

PII: S0028-3908(16)30486-5

DOI: 10.1016/j.neuropharm.2016.11.003

Reference: NP 6498

To appear in: Neuropharmacology

Received Date: 1 September 2016

Revised Date: 28 October 2016

Accepted Date: 1 November 2016

Please cite this article as: Mourre, C., Manrique, C., Camon, J., Aidi-Knani, S., Deltheil, T., TurleLorenzo, N., Guiraudie-Capraz, G., Amalric, M., Changes in SK channel expression in the basal ganglia after partial nigrostriatal dopamine lesions in rats: Functional consequences, Neuropharmacology (2016), doi: 10.1016/j.neuropharm.2016.11.003.

This is a PDF file of an unedited manuscript that has been accepted for publication. As a service to our customers we are providing this early version of the manuscript. The manuscript will undergo copyediting, typesetting, and review of the resulting proof before it is published in its final form. Please note that during the production process errors may be discovered which could affect the content, and all legal disclaimers that apply to the journal pertain. 
Changes in SK channel expression in the basal ganglia after partial nigrostriatal dopamine lesions in rats: functional consequences

Christiane Mourre ${ }^{* a}$, Christine Manrique*b $^{\mathrm{b}}$, Jeremy Camon ${ }^{\mathrm{a}}$, Sabrine Aidi-Knani ${ }^{\mathrm{a}}$, Thierry Deltheil $^{\mathrm{a}}$, Nathalie Turle-Lorenzo ${ }^{b}$, Gaelle Guiraudie-Capraz ${ }^{c}$, Marianne Amalric ${ }^{a}$

a, Aix Marseille Univ, CNRS, LNC, FR3C, Marseille, France

b, Aix Marseille Univ, CNRS, FR3C, 13331, Marseille, France

c, CNRS, Aix Marseille Univ, NICN, 13344 Marseille, France

* Co-first authors contributed equally to this work.

Correspondance to Marianne Amalric:

Laboratoire de Neurosciences Cognitives (LNC), Aix Marseille Université, CNRS, UMR7291, FR3C 3512, Case C, 3, place Victor Hugo, F-13331 Marseille cedex 03, France

Tel: +33 (0) 4135509 35; Fax: +33 (0) 413550958

E-mail: marianne.amalric@univ-amu.fr

Author Keywords: calcium-activated potassium channel, apamin, homeostasis, reaction time, Parkinson's disease

Number of pages: 40

Number of words; Abstract: 276

Number of table: 1 and supplemental data: 1

Number of figures: 5 and supplemental data: 4 


\section{Highlights}

In a rat model of Parkinsonism:

- Upregulation of SK2 channel expression in the subthalamic nucleus

- Decrease of SK3 channel expression level in the substantia nigra pars compacta

Behavioral performance in a reaction time task of 6-OHDA-lesioned rat

- Impairment by SK channel blockade with apamin in the subthalamic nucleus

- Improvement by SK channel blockade with apamin in the substantia nigra pars compacta

\section{Abbreviations:}

6-OHDA, 6-hydroxydopamine

apa, apamin

$B G$, basal ganglia

Col, cytochrome oxidase subunit I

CyPPA, N-Cyclohexyl-N-[2-(3,5-dimethyl-pyrazol-1-yl)-6-methyl-4-pyrimidinamine

DA, dopamine

DAT, dopamine transporter

ISH, in situ hybridization

$\mathrm{K}_{\text {ATP }}$ :ATP-sensitive potassium channels

$P D$, Parkinson's disease

qRT-PCR, quantitative real time polymerase chain reaction

$R T$, reaction time task

SK channels, small-conductance calcium-activated potassium channels

SNC, substantia nigra pars compacta

SNR, substantia nigra pars reticulata

SSC, Saline Sodium Citrate

STN, subthalamic nucleus

$\mathrm{TH}$, tyrosine hydroxylase

VTA, ventral tegmental area 


\section{Abstract}

Parkinson's disease (PD) is a progressive neurodegenerative disease originating from the loss of dopamine (DA) neurons in the substantia nigra pars compacta (SNC). The small-conductance calcium-activated potassium (SK) channels play an essential role in the regulation of midbrain DA neuron activity patterns, as well as excitability of other types of neurons of the basal ganglia. We therefore questioned whether the SK channel expression in the basal ganglia is modified in parkinsonian rats and how this could impact behavioral performance in a reaction time task. We used a rat model of early PD in which the progressive nigrostriatal DA degeneration was produced by bilateral infusions of 6-hydroxydopamine (6-OHDA) into the striatum. In situ hybridization of SK2 and SK3 mRNA and binding of iodinated apamin (SK2/SK3 blocker) were performed at 1, 8 or 21 days postsurgery in sham and 6-OHDA lesion groups. A significant decrease of SK3 channel expression was found in the SNC of lesioned animals at the three time points, with no change of SK2 channel expression. Interestingly, an upregulation of SK2 mRNA and apamin binding was found in the subthalamic nucleus (STN) at 21 days postlesion. These results were confirmed using quantitative real time polymerase chain reaction (qRT-PCR) approach. Functionally, the local infusion of apamin into the STN of parkinsonian rats enhanced the akinetic deficits produced by nigrostriatal DA lesions in a reaction time task while apamin infusion into the SNC had an opposite effect. These effects disappear when the positive modulator of SK channels (CyPPA) is coadministered with apamin. These findings suggest that an upregulation of SK2 channels in the STN may underlie the physiological adjustment to increased subthalamic excitability following partial DA denervation. 


\section{Introduction}

Variation of potassium (K) channel function and expression has recently been related to the abnormal firing of basal ganglia (BG) neurons which is thought to contribute to the expression of Parkinson's disease (PD) (Liu et al., 2010; Surmeier et al., 2007; Wang et al., 2008). K channels, by mediating diverse cellular signaling, are critical determinants of neuronal excitability and neurotransmitter release (Adelman et al., 2012; Pongs, 2008). In the BG, they contribute to maintain basal levels of dopamine (DA) in projection areas by modulating the tonic, low frequency action potentials of dopaminergic neurons. Brief transitions to a burst firing mode result in barrages of high frequency action potentials that transiently elevate DA levels to trigger DAmediated behaviors (Chergui et al., 1994; Schultz, 2002). In animal models of Parkinsonism, variation of gene expression of voltage-gated calcium (KV), ATP-sensitive ( $\left.\mathrm{K}_{\mathrm{ATP}}\right)$ or small conductance calcium-activated (SK) $\mathrm{K}$ channels is found in structures of the BG known to be dysregulated in pathophysiological condition. For example, $\mathrm{K}_{\text {ATP }}$ expression is upregulated in the striatum and the subthalamic nucleus (STN) after DA neurons degeneration in the substantia nigra pars compacta (SNC) in experimental Parkinsonism (Shen and Johnson, 2012; Wang et al., 2005), and in the SNC of Parkinsonian patients (Schiemann et al., 2012). $\mathrm{K}_{\text {ATP }}$ channel opening agents injected into the globus pallidus restore locomotor activity in the reserpine-treated rat model of Parkinson's disease and decrease overactive GABA transmission (Maneuf et al., 1996). In addition, intraperitoneal injection of ATP channel opener partially alleviates haloperidol-induced catalepsy, a rat model of akinesia (Maneuf et al., 1996; Wang et al., 2005). A decrease of Kv4 channeldependent $I_{A}$ current is found after striatal DA depletion that contributes to the enhancement of striatal medium spiny neurons excitability (Azdad et al., 2009; Day et al., 2006). In vivo, we recently demonstrated that local blockade of Kv4 channels in the striatum may reduce the motor and neuropsychiatric impairment of partially DA depleted rats (Aidi-Knani et al., 2015). 
Among $\mathrm{K}$ channels, SK channels play an essential role in the intrinsic properties of BG neurons and particularly in regulating dopaminergic neurons (Pedarzani and Stocker, 2008). They produce a medium afterhyperpolarization following a single action potential and regulate spike frequency adaptation, the frequency and precision of pacemaker activity of DA neurons. They also regulate action potential firing of striatal GABAergic and subthalamic glutamatergic neurons (Deignan et al., 2012; Hallworth et al., 2003; Hopf et al., 2010; Wolfart et al., 2001). BG neurons contain SK channels made up of either SK2 or SK3 subunits, that are sensitive (albeit differentially) to apamin (Sailer et al., 2004). Blockade of SK channels by apamin was recently found to decrease the motor and cognitive impairment induced by nigrostriatal DA depletion (Alvarez-Fischer et al., 2013; Chen et al., 2014). Interestingly, in vitro SK channel activation by NS309 protects human DA neurons submitted to a calcium-dependent neuronal death by inhibiting the mitochondrial complex I with rotenone (Dolga et al., 2014), while SK channel blockade with apamin increases DA neurons survival in mesencephalic cell culture (Salthun-Lassalle et al., 2004).

The aim of the present study was to determinate the potential variation of SK channel subunit expression during the development of the nigrostriatal DA degeneration. Here, we found an increase of SK2 channel expression in the STN after partial 6-OHDA-induced nigrostriatal lesions in rats. Moreover, we analyzed the impact of intracerebral activation or blockade of SK channels in the SNC and the STN on DA lesion-induced impairment of reaction time (RT) performance for which the activation of the STN is essential (Baunez et al., 1995).

\section{Materials and methods}

\subsection{Animals and surgery}


Male Wistar rats (280-300 g) (Charles River Laboratories, l'Arbresle, France) were housed 2/cage and kept at a constant temperature $\left(22^{\circ} \mathrm{C}\right)$ under a $12 \mathrm{~h} / 12 \mathrm{~h}$ light/dark cycle (lights on at 7:00 a.m.). For in situ hybridization (ISH), binding $(n=48)$ and $q R T-P C R$ experiments $(n=21)$, animals were given food and water ad libitum. Each animal was handled (10 $\mathrm{min}$ ) for four days before the start of experiments. For behavioral experiments (e.g. reaction time (RT) task), male Wistar rats ( $\mathrm{n}$ $=80$ ) weighing $175-185 \mathrm{~g}$ at the beginning of the experiment, were fed $15-17 \mathrm{~g} /$ day laboratory chow delivered $3 \mathrm{~h}$ after the testing period, so as to maintain $85 \%$ of their free feeding body weight. Water was provided ad libitum. Animal experimental procedures were in strict accordance with the recommendations of the European Communities Council Directive (2010/63/EU) and conformed to the ethical guidelines of the French National Ethical Committee (authorization \# $A 7 / 12 / 12$ ). All efforts were made to minimize the numbers of animals used and to maintain them in good general health.

\subsection{Nigrostriatal 6-OHDA lesions}

Animals were anesthetized with a subcutaneously injection $(0.33 \mathrm{~mL} / \mathrm{Kg})$ of a combination of medetomidine (1 mg/mL; Janssen) and ketamine (5\%; Virbac, France) and placed in a stereotaxic apparatus (David Kopf instrument, Tujunga, CA, USA) with the incisor bar positioned $3.3 \mathrm{~mm}$ under the interaural line. 6-OHDA hydrobromide (12 $\mu \mathrm{g} / 3 \mu \mathrm{L}$ per side; Tocris Bioscience, Bristol, U.K.) or vehicle $(0.1 \%$ ascorbic acid in $0.9 \% \mathrm{NaCl})$ was bilaterally injected in the striatum at the following coordinates (Paxinos and Watson, 2007): AP $+0.2 \mathrm{~mm}, \mathrm{~L} \pm 3.5 \mathrm{~mm}, \mathrm{DV}-4.8 \mathrm{~mm}$ according to bregma as described previously (Lopez et al., 2012). The flow rate $(0.33 \mu \mathrm{L} / \mathrm{min}$ ) and volume of injections were controlled with a micropump (CMA/100; CMA/Microdialysis, Stockholm, Sweden) using a $10 \mu \mathrm{L}$ Hamilton microsyringe connected by a catheter (Tygon ${ }^{\circledR}$, i.d. $0.25 \mathrm{~mm}$ ) fitting to the 30 gauge stainless steel injector needles. Three additional minutes were allowed for diffusion of 
the toxin. Animals were allowed a 7-d recovery period prior to behavioral testing in the RT task. In situ hybridization studies and binding experiments were performed 1, 8 or 21 days after 6-OHDA lesions, according to previous studies (Blandini et al., 2007).

\subsection{Drug treatment}

Apamin (Genepep, Montpellier, France) and N-Cyclohexyl-N-[2-(3,5-dimethyl-pyrazol-1-yl)-6methyl-4-pyrimidinamine (CyPPA, Sigma-Aldrich, St Louis, MO, USA) were injected intracerebrally in the STN or SN. Rats received bilateral injections of apamin ( 0.05 or $0.1 \mathrm{ng}$ per side, dissolved in a volume of $0.5 \mu \mathrm{L}$, in $0.9 \%$ sterile $\mathrm{NaCl}$, CyPPA (0.5 $\mu \mathrm{g}$ per side, dissolved in Chremophor $^{\circledR} \mathrm{RH} 40$ (10\%) containing ethanol (4\%)) or co-injection of apamin+CyPPA. Doses were chosen on the basis of previous reports (Maurice et al., 2015; Mpari et al., 2008).

\subsection{Tissue preparation}

For in situ hybridization and binding experiments, rats were anesthetized with pentobarbital sodic (6\%, Sanofi santé, France) and their brain removed after decapitation at different postlesion timepoints (e.g. on day 1,8 or 21 ). Brains were immediately frozen on powered dry ice and stored ($80^{\circ} \mathrm{C}$ ) until cryostat sectioning. Coronal sections ( $20 \mu \mathrm{m}$ for apamin and mazindol binding, $12 \mu \mathrm{m}$ for $\mathrm{ISH}$, and $16 \mu \mathrm{m}$ for $\mathrm{TH}$ immunohistochemistry) were collected $\left(-20^{\circ} \mathrm{C}\right)$ onto on Superfrost Plus slides, at level of the striatum, entopeduncular nucleus, STN and SN using a cryostat apparatus (model CM3050; Leica, Wetzlar, Germany) and stored at $-80^{\circ} \mathrm{C}$. Experiments were carried out blind; the group that the rats belonged to was unknown to the person conducting binding and ISH experiments. 
For qRT-PCR, collection of SN and STN samples was adapted from Manrique et al. (2009). Animals were sedated with isoflurane (AErrane, Baxter, Belgium) and brains rapidly removed. The SN and STN were micro-dissected from $2 \mathrm{~mm}$-thick sections, using a specific slicer at $-20^{\circ} \mathrm{C}$. Inside sections, a cylinder ( $1 \mathrm{~mm}$ diameter) was dissected using a micropunch allowing to obtain cylindric samples of $1.6 \mathrm{~mm}^{3}$ following the landmarks of the stereotaxic atlas Paxinos and Watson (2007): $\mathrm{SN}, \mathrm{AP}-5.0 \mathrm{~mm}, \mathrm{~L} \pm 2.0 \mathrm{~mm}, \mathrm{DV}-8.2 \mathrm{~mm}$; STN, AP - $3.8 \mathrm{~mm}, \mathrm{~L} \pm 2.4 \mathrm{~mm}, \mathrm{DV}-8.4 \mathrm{~mm}$ according to bregma. Tissue specimens were placed in RNase-free microcentrifuge tubes, immediately frozen on dry ice and then stored at $-80^{\circ} \mathrm{C}$. Each hemispheric SN were separately collected and analyzed whereas each hemispheric STN were pooled for the analysis.

\subsection{Extent of 6-OHDA lesions}

The extent of the lesions was verified by tyrosine hydroxylase immunohistochemistry of DA neurons at nigral level and by autoradiographic labelling of DA uptake sites with $\left[{ }^{3} \mathrm{H}\right]$-mazindol at striatal level for DA projection in bilateral 6-OHDA-lesioned groups.

\subsubsection{TH immunohistochemistry}

Frozen sections were post-fixated with ice-cold $4 \%$ paraformaldehyde in $0.0 .5 \mathrm{M}$ Tris buffer $(\mathrm{pH}$ 7.4). Following rinsing and preincubation in 0.0.5M Tris solution containing bovine serum albumin (BSA, 10\%), for $1 \mathrm{~h}$, sections were exposed to monoclonal mouse anti-TH (1:3000; IgG, Millipore, USA), $1 \mathrm{~h}$ at room temperature then overnight, $4^{\circ} \mathrm{C}$. Sections were then exposed for $2 \mathrm{~h}$, at room temperature, to biotinylated goat anti-mouse (1/200, Vector, Burlingame, CA, USA, 1h, room temperature), followed by diaminobenzidine visualization method (Elite $A B C$ Kit, Vector), dehydrated in ethanol and xylene, and coverslipped using DePex. Between each incubation, the 
sections were washed several times in $0.05 \mathrm{M}$ Tris buffer with BSA $2 \%$. In control experiments where the primary or secondary antibody was omitted, no labelling was observed.

\subsection{2. $\left[{ }^{3} \mathrm{H}\right]$-mazindol binding}

Binding of $\left[{ }^{3} \mathrm{H}\right]$-mazindol was measured according to the procedure described previously (Breysse et al., 2002; Chen et al., 2014). In brief, sections were first air-dried and rinsed for $5 \mathrm{~min}$ at $4^{\circ} \mathrm{C}$ in $50 \mathrm{mM}$ Tris buffer with $120 \mathrm{mM} \mathrm{NaCl}$ and $5 \mathrm{mM} \mathrm{KCl}$. Then, the sections were incubated for $40 \mathrm{~min}$ with $15 \mathrm{nM}\left[{ }^{3} \mathrm{H}\right]$-mazindol (PerkinElmer, Boston, MA, USA; specific activity: $722 \mathrm{GBq} / \mathrm{mmol}$ ) in 50 $\mathrm{mM}$ Tris buffer containing $300 \mathrm{mM} \mathrm{NaCl}$ and $5 \mathrm{mM} \mathrm{KCl}$ added with $0.3 \mathrm{mM}$ desipramine to block the noradrenaline transporter. Sections were rinsed twice for $3 \mathrm{~min}$ in the incubation medium without mazindol, once for $10 \mathrm{~s}$ in distilled water and were then air-dried. Finally the sections were left in contact for 50 days to a specific Kodak BioMax MR $\left[{ }^{3} \mathrm{H}\right]$--sensitive film screen to generate autoradiograms. Cresyl-violet staining of sections was used to locate the trace of the 6OHDA injector needle.

\subsection{SK expression}

In order to investigate variations of SK expression after bilateral 6-OHDA lesions, we used $\left[{ }^{125}\right.$ I]apamin binding for protein expression and ISH with radiolabeled probes of SK $\alpha$-subunit probes, associated with qRT-PCR, for SK2 and SK3 mRNA gene levels. For each autoradiographic experiment, brain sections were collected at the level of four brain regions (striatum and globus pallidus, entopeduncular nucleus, subthalamic nucleus, and midbrain regions) of six groups (sham or 6-OHDA-lesioned groups at three time-points: 1,8 and 21 days postlesion, $n=8$ per group). Then, to prevent experimental artifacts during analysis of the autoradiograms, the sections of each 
region were submitted to the same apamin binding or ISH experiment and exposed side by side on the same autoradiographic film at each time point.

\subsection{1. $\left[{ }^{125}\right.$ I]-apamin binding}

For binding experiments, tissue sections were incubated with highly radioactive apamin labeled with $\left[{ }^{125}\right.$ I] (PerkinElmer, NEN Life Science Products, Boston, MA, USA) as previously described (Mourre et al., 1986). Brain sections were incubated with 25 pM [ $\left.{ }^{125} \mathrm{I}\right]$-apamin (specific activity, 81.4 TBq/mmol), at $4{ }^{\circ} \mathrm{C}$ in $100 \mathrm{mM}$ Tris- $\mathrm{Cl}$ buffer, containing $0.5 \%$ bovine serum albumin (BSA), $\mathrm{pH}$ 7.4. Nonspecific binding was assessed by adding a large excess of native apamin (0.1 $\mu \mathrm{M}$, SigmaAldrich, St Louis, MO, USA), before adding $\left[{ }^{125} \mathrm{I}\right]$-apamin. Sections were incubated for $60 \mathrm{~min}$ and rinsed three times, each for $20 \mathrm{~s}$, in the same buffer. The sections were rinsed a fourth time, for 20 $\mathrm{s}$, in water. Dried sections were placed on Kodak BioMax MR Films. Serial sections of one naive rat were added with experimental sections, serving as internal standards for labeling at the different time-points. Autoradiograms were exposed for 12 days to obtain unsaturated labeling and thus to allow the detection of increases or decreases in labeling. Films were then processed in a Kodak Industrex developer. Cresyl violet stained sections were used for reference and to locate the trace of the 6-OHDA injection and cannula implantations.

\subsubsection{In situ hybridization of SK mRNA}

2.6.2.1. Oligonucleotide probes. Oligodeoxynucleotide probes for the rat SK2 $\alpha$-subunits were purchased from Eurogentec S.A. (Angers, France) and purified by reverse phase chromatography. Oligodeoxynucleotide probes (45 mers) corresponding to 5 ' regions for each SK subunit were as follows: $\quad$ 5'-AGC-GCC-AGG-TTG-TTA-GAA-TTG-TTG-TGC-TCC-GGC-TTA-GAC-ACC-ACG-3' (SK2), $5^{\prime}$ - 
those used in a previous study (Stocker et al., 1999; Stocker and Pedarzani, 2000). The probes targeted a coding region of the SK $\alpha$-subunit mRNA at nucleotide residues 233-189 (SK2) and 2036-1992 (SK3) of the published cDNA sequence (Köhler et al., 1996). The sense oligodeoxynucleotide was used as a negative control. Probe specificity was determined with the public domain program "BLAST". The sequences did not display any significant similarity with other sequences in the databases. Probe cDNA fragments were prepared by labeling the cDNA fragment by the random primer method with $\left[{ }^{35} \mathrm{~S}\right]-\alpha \mathrm{S}-\mathrm{dATP}(48.1 \mathrm{TBq} / \mathrm{mmol})$ using a DNA-tailing kit (PerkinElmer Inc, NEN Life Science Products, Boston, MA, USA) and terminal deoxynucleotide transferase (Roche Diagnostics, Meylan, France). The radiolabeled probes were then purified by gel-filtration chromatography and centrifugation (Quick Spin Columns, Roche). Radiolabeled probes were then stored at a specific activity (at least $1 \times 10^{6} \mathrm{cpm} / \mu \mathrm{l}$ ) at $4^{\circ} \mathrm{C}$.

2.6.2.2. In situ hybridization procedures. All solutions were treated with diethylpyrocarbonate and autoclaved to avoid RNase degradation. Slide-mounted sections were postfixed at $4^{\circ} \mathrm{C}$ for $5 \mathrm{~min}$ in $4 \%$ paraformaldehyde and were rinsed twice, for $5 \mathrm{~min}$ in a phosphate saline buffer $(\mathrm{pH} 7.2)$. The sections were then acetylated for $10 \mathrm{~min}$ with $0.25 \%$ acetic anhydride in $0.1 \mathrm{M}$ triethanolamine $(\mathrm{pH} 8)$ and dehydrated in ethanol. After chloroform treatment, the sections were dried in a dessicator. Each section was covered with the DNA labeled probe $\left(5 \times 10^{5} \mathrm{cpm} / \mathrm{section}\right)$ diluted in $35 \mu$ of hybridization solution ( 4 x Saline Sodium Citrate (SSC) containing $50 \%$ formamide, $10 \%$ dextran sulfate, $1 \times$ Denhardt's solution, $5 \mathrm{mg} / \mathrm{mL}$ E. coli tRNA and $2.5 \mathrm{mg} / \mathrm{mL}$ sheared salmon sperm DNA), and incubated for $12 \mathrm{~h}$ at $47^{\circ} \mathrm{C}$ for SK2 probes or at $44^{\circ} \mathrm{C}$ for SK3 probes in humid chambers. Afterwards, sections were rinsed in cold $2 \times$ SSC, then in $1 \times$ SSC at room temperature for $10 \mathrm{~min}, 1 \times \mathrm{SSC}$ for $30 \mathrm{~min}$ at $55^{\circ} \mathrm{C}$, with one further wash in $1 \times \mathrm{SSC}$ at room temperature, and 
a final wash in $0.1 \times$ SSC at room temperature. Sections were dehydrated with a graded ethanol series and air-dried. Slides were exposed to Kodak Bio-Max MR-1 film for 15 days in the presence of $\left[{ }^{14} \mathrm{C}\right]$ plastic standards (Amersham, UK). The exposure times were adjusted to avoid film saturation and to obtain labeling of intermediate intensity to quantify changes. Kodak BioMax MR Films were developed with Kodak GBX solution for $3 \mathrm{~min}$ at $20^{\circ} \mathrm{C}$, rinsed, and fixed. Cresyl violet stained sections were used for reference.

\subsubsection{Quantitative real time polymerase chain reaction}

2.6.3.1. Primer design. In order to investigate potential variations of SK2, SK3 gene expression levels, 21 days following bilateral 6-OHDA lesions, we used YWHAZ as our reference gene. The YWHAZ gene encodes for the tyrosine 3-monooxygenase/tryptophan 5-monooxygenase activation protein zeta polypeptide. YWHAZ is a reference gene recently tested for its stability (Langnaese et al., 2008; Nelissen et al, 2010). To ascertain the nigral DA cell loss, the expression level of the dopamine transporter dopamine transporter (DAT) gene was also included in the study. Primers used in this study were either designed with PRIMER 5 software or the same as those designed by Langnaese et al. (2008) and Nelissen et al. (2010). Primer oligonucleotides were purchased from Eurogentec (Angers, France). The sequences of the primers are listed in Table S1.

2.6.3.2. Total RNA isolation and CDNA synthesis. Total RNA was isolated from the SN and STN using Tri-Reagent (Sigma-Aldrich, St Louis, MO, USA) according to the manufacturer's recommendations and dissolved in $20 \mu \mathrm{L}$ of nuclease-free water. The concentration of total RNA was determined by measuring the optical density at $260 \mathrm{~nm}$ (SmartSpec ${ }^{\mathrm{TM}} 3000$ Spectrophotometer, Bio-Rad Laboratories, Marnes-la-Coquette, France) and the purity was checked as the $260 \mathrm{~nm} / 280 \mathrm{~nm}$ ratio with expected values between 1.8 and 2.0. The integrity of total RNA was assessed by electrophoresis on $1.2 \%(\mathrm{w} / \mathrm{v})$ agarose gels. To remove potential DNA contamination, RNA 
samples were DNase Treated (DNA-Free ${ }^{\mathrm{TM}}$, Ambion, Thermo Fisher Scientific, Illkirch, France). 300

ng of RNA were subjected to reverse transcription using iScript ${ }^{\mathrm{TM}}$ CDNA Synthesis Kit (Bio-Rad Laboratories, Marnes-la-Coquette, France). The product was then diluted with RNase-free water to a cDNA concentration of $50 \mathrm{ng} / \mu \mathrm{L}$.

2.6.3.3. Quantitative Real time polymerase chain reaction. Relative expression of SK2, SK3 and DAT genes in the SN and the STN was carried out by qRT-PCR analyses using the MiniOpticon ${ }^{\text {TM }}$ System (Bio-Rad Laboratories, France) in $25 \mu \mathrm{L}$ reactions containing $300 \mathrm{nM}$ of the gene specific primers for SK2, SK3, DAT and YWHAZ, $2 \mu \mathrm{L}$ of cDNA template in a master mix (iQ SYBR Green Supermix, Bio-Rad Laboratories, Marnes-la-Coquette, France). After an initial denaturation step at $95^{\circ} \mathrm{C}$ for 3 min, amplifications were performed with 40 cycles of $10 \mathrm{~s}$ at $95^{\circ} \mathrm{C} / 30 \mathrm{~s}$ at $50^{\circ} \mathrm{C}$. For each sample, SYBR Green qRT-PCR was conducted in triplicate and melting curves were included to ascertain the formation of a single product from each gene. "No template controls", in which no cDNA template is added, were also performed for each mix prepared. Primer efficiencies were determined by a standard curve of samples according to the MIQE guidelines for qRT-PCR (Bustin et al., 2009). Data were evaluated with the MiniOpticon CFX Manager ${ }^{\mathrm{TM}}$ V2.0 software (Bio-Rad Laboratories, Marnes-la-Coquette, France) by the delta-delta $C_{T}$ method that measures the expression level of the target gene normalized to the reference gene YWHAZ and relative to the expression of the target gene in a calibrate sample (sham).

\subsection{Reaction Time task procedure}

Eight operant boxes (Campden Instruments, Cambridge, UK) were used for the reaction time (RT) task. Each box was equipped with a retractable lever, a food magazine and a cue light ( $2.8 \mathrm{~W}$ bulb) located above the lever corresponding to the response signal. The lever required a force of $0.7 \mathrm{~N}$ for switch closure. A house light located on the ceiling was turned on at the beginning of the 
testing session. Each box was placed in a wooden sound-attenuating cabinet that was ventilated by a low-level noise fan in order to reduce outside noise. Food restriction was introduced at the beginning of the training period. Rats were trained daily for 3 months to quickly release the lever after the visual cue onset presented after four randomly and equiprobably generated foreperiods $(0.5,0.75,1.0$, or $1.25 \mathrm{~s})$ to be rewarded by a $45 \mathrm{mg}$ food pellet (P.J. Noyes Company, Inc., Lancaster, NA, USA). Performance was measured by recording the number of correct and incorrect (non-rewarded) responses either "premature," corresponding to early withdrawal of the lever (before the onset of the response signal), or "delayed," when the lever was released after the 600 ms time limit. Each daily session ended after 100 trials. Premature responses were recorded independently and were not limited. At the end of training period, rats were tested for 5 consecutive days in the RT task to measure preoperative baseline values before lesion.

All the animals were then subjected to the 6-OHDA lesion procedure as described above. During the same surgery, they were also implanted with $10 \mathrm{~mm}$ bilateral stainless steel guide cannulas (23 gauge) positioned $3 \mathrm{~mm}$ above the injection site in the STN or the SNC at the following coordinates: STN: (AP) $-3.8 \mathrm{~mm},(\mathrm{~L}) \pm 2.4 \mathrm{~mm}$ and (DV) $-5.4 \mathrm{~mm}$ according to bregma; SNC: (AP) $5.0 \mathrm{~mm},(\mathrm{~L}) \pm 2.0 \mathrm{~mm}$ and (DV) $-5.2 \mathrm{~mm}$ according to bregma. The guide cannulas were then anchored to the skull with four stainless steel screws and dental cement. Stainless steel wire inlet cannulas $(10 \mathrm{~mm})$ were placed inside to prevent occlusion. After an 8-day recovery period, postoperative performance was recorded daily for 30 days. Sham $(n=35)$ and 6 -OHDA $(n=45)$ animals were divided into subgroups receiving intracerebral injection of vehicle, apamin $(0.1$ or 0.2 ng), CyPPA (1 $\mu \mathrm{g})$ and apamin + CyPPA solutions into the STN or the SNC at postsurgical days 16, 20, 24 and 28. Bilateral intrasubthalamic or intranigral injections of apamin or CyPPA, were performed with stainless steel injector needles (13 mm, 30 gauge) inserted inside the implanted guide cannulas and fitted so that they protruded $3 \mathrm{~mm}$ below, into the STN or the SN area. The sites of injection in the STN and SNC are illustrated in Figure S1. Before each testing day, the 
animals were gently maintained while inserting the injectors into the bilateral implanted guide cannulas. Injectors were connected via a polyethylene catheter (Tygon ${ }^{\circledR}$, i.d. $0.25 \mathrm{~mm}$ ) to Hamilton microsyringes $(10 \mu \mathrm{L})$ fitted to a micropump (CMA/100, Stockholm, Sweden). The flow delivered by the pump was set at $0.16 \mu \mathrm{L} / \mathrm{min}$ for a volume of $0.5 \mu \mathrm{L} /$ side. At the end of injection, injector needles were left in place for 3 more min. to allow the diffusion of the solution. Immediately afterwards, inlet cannulas were replaced and the performance in the RT task was recorded.

\subsection{Data analysis}

\subsubsection{TH immunohistochemistry}

Quantification of TH immunostaining was performed by digitized image analysis of the nigral sections via computer-assisted image analysis using a Leitz Aristoplan light microscope (Leica Microsystems, Wetzlar, Germany) equipped with a DXM 1200 Nikon high-resolution digital camera (1024 x1024 pixels; Nikon, Tokyo, Japan) interfaced to a PC computer employing image software for capturing and processing the images (Lucia G, Nikon, Champigny-sur-Marne, France). The recorded images were further used for estimation of the number of individual $\mathrm{TH}$-immunoreactive cell. Using Image J 1.36b imaging software (NIH, Bethesda, MD, USA), after a delimitation of SNC nucleus, the total area of this nucleus was assessed as a pixel number in each side of sections at four consecutive levels, spending the rostra-caudal extent of the nucleus (from -4.7 to $-5.9 \mathrm{~mm}$ with respect to the bregma). Then, only $\mathrm{TH}$ immunoreactive cells with visible nuclei were taken into account. Survival DA neuron values, expressed as number of TH-positive cells by section and averaged for each rat, were analyzed independently by two experimenters blind to the treatment groups. In addition, cell counts were performed on Cresyl violet-stained neurons in the SNC and the ventral tegmental area (VTA) on alternate sections. 


\subsection{2. $\left[{ }^{3} \mathrm{H}\right]$-mazindol binding}

The extent of bilateral nigrostriatal 6-OHDA lesions was estimated by delimitating the lesioned area in each hemisphere as the sum of pixels with low gray levels at least five rostro-caudal striatal levels per animal (from 2.3 to $-1.6 \mathrm{~mm}$ according to the bregma). The level of the lesion was determined as the ratio between the lesioned and total striatum areas, expressed as the percentage of the total striatal surface assessed as a pixel number. As no difference was found in either the surface measured on each side of the brain, the values obtained were averaged. Then, a mean \pm standard error of the mean (S.E.M.) was calculated for each experimental group.

\subsection{3. $\left[{ }^{125}\right.$ I]-apamin binding}

Autoradiograms were analyzed and radioactivity quantified with $\mathrm{NIH}$ Image software. $\left[{ }^{14} \mathrm{C}\right]$ Plastic standards were used to calibrate $\left[{ }^{125} \mathrm{I}\right]$ concentrations. Mean receptor density was calculated for each nucleus, using six to eight bilateral measurements in each animal. The group value presented for each structure studied is the mean of values obtained for each animal \pm S.E.M. Non-specific binding was detected on autoradiograms of sections incubated with unlabeled $0.1 \mu \mathrm{M}$ apamin, corresponding to around $15 \%$ of total binding. Specific binding was calculated as the difference between total and non-specific binding for a given area. Rat brain regions were identified and named using a rat brain atlas (Paxinos and Watson, 2007).

\subsubsection{SK2 and SK3 mRNA in situ hybridization}

Film autoradiograms were scanned and hybridization signal quantified using NIH image software; the observer was blind to the conditions of the experiment. The gray areas corresponding to mRNA labeling were quantified using $\left[{ }^{14} \mathrm{C}\right]$ plastic standards to calibrate $\left[{ }^{35} \mathrm{~S}\right]$ relative concentration. mRNA labeling was expressed in relative units. Mean value \pm S.E.M. was calculated 
for each brain structure in each hemisphere, using three unilateral measurements in each animal. We observed non-specific hybridization in negative control sections (sense probe), i.e. these sections displayed a weak, uniform labeling pattern, which did not follow neuroanatomical landmarks.

\subsubsection{Reaction time task}

The effects of dopamine depletion and drug injections on RT performance were evaluated on the number of correct and incorrect responses (delayed responses) averaged across each session. For pre- and postoperative conditions, we averaged the performance measured during 5 consecutive sessions before (pre) and after surgery (post). Because there was no difference between the five sessions either in the "pre" or the "post" conditions for any variable, the performance was thus compared with that measured after apamin, CyPPA or vehicle injection into the STN or the SN.

\subsection{Statistical analysis}

Using Graphpad Prism6 software, the effects of 6-OHDA lesions on expression were tested by means of one-way analysis of variance (ANOVA) or two-way ANOVA, followed by adapted posthoc tests between groups (Tukey or Holm-Sidak test). Student's $t$ test was used to analyze the effects of 6-OHDA compared to sham groups injected with vehicle. The paired t-test was used to analyze and to compare the expression level of SK2, SK3 and DAT genes. Simple-regression analysis was used to identify correlations between 6-OHDA lesions or TH immunoreactivity levels and changes in mRNA level. The effect of drug treatment on behavioral performances were submitted to two-way ANOVA with groups (sham vs 6-OHDA) as the between-subject factor, and 
conditions (pre, post, vehicle, apamin or CyPPA) as the within-subject factor, followed by post-hoc multiple comparisons test (Holm-Sidak test) as appropriate. All data were expressed as the mean \pm S.E.M. and a P value of $<0.05$ was taken as the minimum level of significance.

\section{Results}

\subsection{Evaluation of 6-OHDA lesions extent}

The lesion extent in the SNC and striatum was analyzed at three time-points $(1,8$, and 21 days postlesion). The decrease of TH-positive cells was found along the whole rostro-caudal axis (Fig. 1A). No significant difference was found between the number of TH-positive cells in the SNC of the left and right side of the brain, therefore the data were pooled per rat. In the SNC, the group $x$ time ANOVA revealed a significant interaction $\left(F_{2,41}=4.22, P<0.05\right)$ and a main effect of lesion $\left(F_{1,41}=72.83, P<0.01\right)$ and no time effects $\left(F_{2,41}=2.33\right.$, NS) (Fig. 1B). Compared to sham groups, Tukey test showed that the number of TH-positive cells was significantly reduced by $19.5 \pm 0.72 \%$ at days 1 and $8(P<0.05)$ and by $37 \%$ at day 21 following $6-$ OHDA lesions $(P<0.05)$. The decrease at day 21 was significantly different from that observed on day $1(P<0.05)$. No significant change was found in the VTA (data not shown). Bilateral infusion of 6-OHDA in the striatum produced a loss of DA nerve terminals restricted to its dorsal part, extending to the rostro-caudal axis of the striatum, as shown by decreased $\left[{ }^{3} \mathrm{H}\right]$ mazindol binding to dopamine uptake sites, expressed as percentage of lesioned area, by $33.6 \pm 1.72 \%$ compared with sham animals whatever the studied time-points (Fig. 1C and 1D). These data are consistent with the decrease of endogenous striatal DA contents assessed by HPLC (Amalric et al., 1995). No difference was found between the levels of mazindol binding in the striatum at the three time-points after 6-OHDA lesions $\left(F_{2,21}=0.67, N S\right)$. 
Regression analysis revealed a negative correlation between the levels of mazindol binding and the number of TH-positive cells of 6-OHDA-lesioned rats at 21 days postlesion only $(\mathrm{P}<0.05)$ (Fig. 1E) (e.g. the lowest TH-positive cell density, the more extensive lesioned striatal area). Moreover, qRT-PCR was used to investigate the changes of mRNA expression of DAT in 6-OHDA-lesioned and sham groups at 21 days postlesion. Dopamine transporter (DAT) RNA expression in the SNC was significantly reduced to $36.62 \pm 5.17 \%$ in 6 -OHDA-lesioned animals when compared with sham animals.

\subsection{Variations of SK channel protein and SK mRNA expression following 6-OHDA lesions}

\subsubsection{Apamin binding}

As previously reported (Mourre et al., 1986; Mpari et al., 2008), [ $\left.{ }^{125} \mathrm{I}\right]$-apamin binding sites that correspond to SK2 and SK3 channels, were unevenly distributed in the rat brain (Fig. 2, Table 1). In the basal ganglia, apamin binding sites were found at high levels in the SNC. The density of apamin binding sites in the STN, striatum, and thalamus was intermediate and low in the globus pallidus. In the SNC, a two-way ANOVA revealed an effect of postlesion time $\left(F_{2,41}=8.98, P<0.01\right)$ and of lesion $\left(F_{1,41}=5.24, P<0.05\right)$ but no significant interaction $\left(F_{2,41}=2.63, P=0.08\right)$ on the apamin binding site level. A Tukey test showed that 6-OHDA infusion significantly reduced apamin binding compared to that of vehicle infusion $(-12 \%)$ at 21 days postlesion $(P<0.05)$ (Fig. 3A) but not at 1 and 8 days postlesion (Table 1). At this time-point, apamin binding in the SNC of 6-OHDA-lesioned group was also lower than that at 8 days postlesion $(P<0.05)($ Table 1$)$. A well-defined correlation was found between the TH-immunoreactivity density in the SNC and the apamin binding level at 21 days postlesion ( $\mathrm{P}=0.02)$ (Fig. $3 \mathrm{~A})$. 
In the STN, an increase of apamin binding $(+14 \%)$ was detected in the 6-OHDA-lesioned group compared to sham group, at 21 days postlesion only (Table1, Fig 4A). Indeed, data analysis revealed a lesion $\left(F_{1,41}=5.70, P<0.05\right)$ and postlesion time effect $\left(F_{2,41}=8.17, P<0.01\right)$ with no lesion $x$ time interaction $\left(F_{2,41}=0.36, N S\right)$. Variations of SK channel protein amount in the STN were related to the DA neuronal degeneration in the SNC. A negative correlation between apamin binding level in the STN and TH immunoreactivity density of the SNC was found ( $<<0.01$ ) (Fig. 4A). When the number of TH-positive cells was low in the SNC, apamin binding was high in the STN. No significant interaction, lesion or postlesion time effect was found between 6-OHDA-lesioned and sham groups for the dorsal and ventral striatum, entopeduncular nucleus, globus pallidus, substantia nigra pars reticulata and VTA (two-way ANOVA, $F_{2,41} \leq 3.32$, NS; $F_{1,41} \leq 3.51$ NS; $F_{2,41} \leq 2.92$, NS, respectively)(Table 1).

\subsubsection{SK2 mRNA expression}

In situ hybridization labeling of SK2 mRNA was found at intermediate to low levels in the BG nuclei including the SNC and STN (Fig. 2, Table 1). As previously observed for SK channel protein, no difference in the levels of SK2 mRNA was found at the two first time-points following 6-OHDA lesions compared to sham groups and regardless of the structure (Table 1). At 21 days postlesion, no difference of SK2 mRNA levels was found either in the SNC (Fig. 3B), the SNR, striatum, entopeduncular nucleus or the VTA (Table 1). In contrast, in the STN, there was a significant variation of SK2 mRNA expression of 6-OHDA-lesioned animals, as revealed by a postlesion days $\mathrm{x}$ group interaction $\left(F_{2,41}=6.21, P<0.01\right)$. At 21 days postlesion, a significant increase $(+18 \%)$ of SK2 mRNA expression in the STN of 6-OHDA-lesioned group was found when compared to the sham group (Fig. 4B, Table 1) and to 6-OHDA-lesioned groups at the two other time points (Tukey test, $\mathrm{P}$ $<0.05)$. Linear regression showed a correlation between SK2 mRNA levels in the STN and TH immunoreactivity density of the SNC ( $P=0.004$, Fig. 4B). No such correlation was observed with 
SK2 mRNA levels in the SNC (Fig. 3B). The increase of SK2 mRNA expression in the STN was related to the decreased TH-positive cells in the SNC. Moreover, qRT-PCR analyses confirmed the enhancement of SK2 expression level in the STN of 6-OHDA-lesioned group by 45\% (Fig. 4D) compared to sham group while no difference was found in the SN (Fig. 3D). Linear regression showed a negative relationship between nigral DAT and SK2 expression levels in the STN (Fig 4D).

\subsubsection{SK3 mRNA expression}

High levels of SK3 mRNA expression were found in the SNC and VTA and low to intermediate densities in the other structures of the BG (Fig. 2). No significant difference was detected between in situ hybridization labelling of SK3 mRNA in the studied brain structures of 6-OHDA-lesioned and sham groups at 1, 8, and 21 days postlesion except for the SNC and VTA (Table 1).

In the SNC, a two-way ANOVA revealed a main effect of lesion $\left(F_{1,41}=48.59, P<0.001\right)$ and of postlesion time $\left(F_{2,41}=4.36, P<0.05\right)$ but not interaction $\left(F_{2,41}=1.23, N S\right)$. Whatever the postlesion time-points, SK3 mRNA levels in this structure were lower in the 6-OHDA-lesioned groups compared to sham groups $(-29,-24,-41 \%$ at $1,8,21$ days respectively) (Tukey test, $\mathrm{P}<0.05)$ (Fig. 3C and S2, Table 1). SK3 mRNA level was positively related to TH-positive cell density in the SNC. The lower the TH-positive cell density, the higher decrease of SK3 mRNA expression level was observed $(P<0.05)$ (Fig. $3 C$ and S2). These results were confirmed by qRT-PCR analyses at 21 days postlesion. SK3 mRNA expression level in the SN of 6-OHDA-lesioned group significantly decreased by $43 \%$ compared to sham group (t test, $\mathrm{P}<0.05$ ) (Fig. $3 \mathrm{D}$ ). Moreover, this reduction was positively correlated with that of DAT levels $(P<0.05)$.

At 21 days postlesion, a $21 \%$ decrease of SK3 mRNA expression was also found at the level of the VTA, with a trend already observed at days 1 and 8 . A main effect of lesion $\left(F_{1,40}=11.5, P<0.01\right)$ and postlesion time effect $\left(F_{1,40}=9.30, P<0.01\right)$ but no interaction $\left(F_{2,40}=0.58, N S\right)$ were found 
(Table 1). No variation of SK3 expression was found in the STN whatever the postlesion time (Table1, Fig. 4C).

\subsection{Modulation of SK channel activity on Parkinsonian symptoms}

The behavioral effects of the partial bilateral 6-OHDA lesions were examined by testing the performance of rats previously trained for several months to release a lever after the presentation of a visual cue with rapid RTs, for food reinforcement (Amalric et al., 1995). While performance of sham-operated groups was unchanged after lesion, an increase in the number of incorrect responses (e.g. delayed response over the time limit of $600 \mathrm{~ms}$ ) was observed in the different lesioned groups as early as 8 days after the lesion. This effect lasted for over 30 days postlesion and was significantly different from preoperative or sham levels of performance (Fig. 5). The ANOVA revealed a significant main effect of group, $S N$ group 1 (apa dose-response): $F_{1,17}=12.86$ and group 2 (apa+CyPPa) $F_{1,12}=6.20$ and STN: $\left.F_{1,27}=10.19, P<0.05\right)$. Lengthening of RTs was also observed (pre: $310-330$ ms to post: $360-380$ ms, data not shown). Similar disruption of RTs was previously measured in parkinsonian patients tested in simple RT tasks (Evarts et al., 1981) indicative of the akinetic symptoms of the disease. Premature responses (responses before the visual cue onset) were not modified by the lesion.

\subsubsection{Effect of SK channel modulation in the substantia nigra on reaction time performance}

We first tested the effects of SK channel blockade with different doses of apamin directly injected in the SNC on RT performance of lesioned and sham animals (illustrated in Fig. S3). The animals with injection sites located above or below the SNC were discarded from statistical analyses. Apamin 0.1 or $0.2 \mathrm{ng}$ did not modify RT performance of sham animals. As previously found, an increase of the number of delayed responses was produced by partial 6-OHDA nigrostriatal lesions 
(Baunez et al. 1995). Apamin at a dose of $0.1 \mathrm{ng}$ failed to attenuate the deficits induced by the lesions as the number of delayed responses remained significantly higher than in sham animals (Holm-Sidak test, $P<0.05$ after a significant main group effect, ANOVA, $F 1,18=12.48(P<0.05)$ (Fig. S3). At a dose of $0.2 \mathrm{ng}$, however, apamin dramatically reduced the number of delayed responses that was no longer different from the level of the sham group. The reduction was close to significantly different from postoperative levels ( $P=0.05, \mathrm{Holm}$-Sidak test, Fig. S3). Interestingly, in a few animals $(n=4)$ where the injection sites were located ventrally in the SNR, apamin had no effect on RT performance (data not shown). In a second group of animals, we further tested the effects of apamin $0.2 \mathrm{ng}$ injections in the SNC on behavioral performance and challenged these animals with the SK channel positive modulator, CyPPA at a dose of $1 \mu \mathrm{g}$ (Fig. 5A). As previously found, apamin $0.2 \mathrm{ng}$ reduced the number of delayed responses induced by the 6-OHDA lesions which reached $22 \%$ of the total responses after surgery or after local $\mathrm{NaCl}$ injection (significant difference between 6-OHDA-lesioned and sham groups, $\mathrm{P}<0.05$ Holm-Sidak test, after significant main group effect $F_{1,12}=24.07$, Fig. $5 A$ ). Activation of SK channels with CyPPA in the SNC of sham or 6-OHDA-lesioned animals had no effect on its own. When jointly administered with apamin $0.2 \mathrm{ng}$, however, CyPPA tended to counteract the antiakinetic action of apamin.

\subsubsection{Effect of SK channel modulation in the subthalamic nucleus on reaction time performance}

SK channel blockade with apamin $(0.1 \mathrm{ng})$ or activation with CyPPA (1.0 $\mu \mathrm{g})$, either separately or conjointly injected in the STN, significantly disrupted RT performance of 6-OHDA-lesioned subjects when compared with sham-operated subjects (Fig. 5B). The overall ANOVA revealed a main group effect $\left(F_{1,27}=33.30, P<0.01\right)$, a main treatment effect $\left(F_{4,108}=2.95, P<0.05\right)$ and close to significant group $x$ treatment interaction $\left(F_{4,108}=2.36, P=0.05\right)$. The increased number of delayed responses produced by bilateral striatal 6-OHDA lesions was further enhanced by $29.5 \%$ by apamin 
treatment in comparison to $\mathrm{NaCl}$ injection (Holm-Sidak test, $\mathrm{P}<0.05)$. In contrast, activation of SK channels with CyPPA reduced the number of delayed responses produced by the lesion and no more difference was observed with sham animals injected with the same dose of CyPPA (HolmSidak test, NS). Likewise, no significant effect of single or joint apamin and CyPPA treatment was found in sham-operated animals. Interestingly, the deleterious effect on RT performance produced by SK channel blockade was reduced when CyPPA was jointly administered with apamin. Although this effect did not reach significant level in comparison to apamin single treatment (e.g. the subjects were still unable to release the lever in due time like lesioned animals injected with vehicle), the lower impairment indicates that SK channels activation might counteract apamininduced effect. To verify if repeated intra-cerebral injections could modify RT performance over time, we conducted a new set of experiments with a group of 6-OHDA-lesioned animals and shams that received only the respective vehicle injections of apamin and CyPPA at the same postoperative days. There was no significant difference of vehicle injections on behavioral performance of the two groups over time (Fig. S4).

\section{Discussion}

In rats with a partial nigrostriatal DA denervation, a significant decrease of SK3 channel expression level is found in the substantia nigra pars compacta (SNC) with no change in SK2 channel expression. At 21 days postlesion, an upregulation of SK2 mRNA expression and apamin binding sites is found in the subthalamic nucleus (STN). Behavioral studies show that the blockade of SK2/SK3 channels with apamin infusion into the STN of parkinsonian rats enhances the deficits produced by nigrostriatal DA lesions in the reaction time task, while apamin in the SNC has opposite effects on RT performance. These effects disappear when the positive modulator of SK channels CyPPA is co-administered with apamin. 


\subsection{Partial nigrostriatal degeneration modulates SK channels expression in the basal ganglia}

The motor symptoms of Parkinson's disease classically emerge when $58-64 \%$ of the SNC dopaminergic neurons have degenerated (McGeer et al., 1988). In rodents, mimicking a relatively early stage of PD is particularly challenging in view of the disabling cognitive and affective symptoms occurring during the premotor phase of the disease (Chaudhuri et al., 2011). In our rat model of PD based on bilateral intrastriatal infusion of the catecholamine neurotoxin 6-OHDA in the striatum, a restricted loss of tyrosine hydroxylase (TH)-positive neurons (19\%) occur as early as one day postlesion and gradually increase over time to $37 \%$. Interestingly, the reduction of DAergic fibers in the striatum is occurring at the same time and the loss of around $35 \%$ of DA uptake sites is circumscribed to the dorsal part of the striatum that is maintained for up to 21 days postlesion. The reduction of TH-positive fibers and DA levels in the striatum follows a similar timecourse in earlier studies following bilateral (Amalric et al., 1995; Bonito-Oliva et al., 2014; Tadaiesky et al., 2008) or unilateral intrastriatal 6-OHDA infusions (Blandini et al., 2007; Rosenblad et al., 2000; Stott and Barker, 2014). This partial and progressive loss of nigral TH-positive neurons, although not similar to the human pathology, may help to detect early changes in the disease at cellular and behavioral levels.

Here we confirm that SK2 and SK3 channel subunits are present in the basal ganglia nuclei with different densities of mRNA expression and channel protein (Sailer et al., 2004; Stocker and Pedarzani, 2000) and that apamin binding levels are correlated with the distribution of SK channel protein (Mourre et al., 1986; Sailer et al., 2004). A regional differentiation in the basal ganglia of sham control animals is found with high density of SK3 channels in the SNC and SK2 channels in the STN, with intermediate to low density in the other structures. Interestingly, the main effect 
produced by partial 6-OHDA dopaminergic lesion is to induce opposite changes of apamin binding sites, SK2 and SK3 channel expression in the SNC and the STN.

\subsection{Decrease of SK channel expression in the substantia nigra}

In the substantia nigra, nigrostriatal 6-OHDA lesions reduced the expression of apamin binding sites and SK3 channels. The decrease of SK3 channel subunits expression is correlated to the progressive loss of DA neurons at the three postlesion time points. There was no alteration of SK2 channel expression at the histological resolution used here. SK3 is highly enriched in DA neurons with high density on the soma and dendrites (Wolfart et al., 2001), which explains the progressive loss of SK3 channel expression produced by the dopaminergic nigrostriatal lesions. SK2 channels may also be expressed at very low densities and only on distal dendrites of DA neurons (Deignan et al., 2012) and more extensively in the SNR. The decrease of SK3 mRNA expression measured at 1 and 8 days postlesion ( 29 and $24 \%$ respectively) is not observed at the channel protein level as the apamin binding site is only significantly reduced at 21 days postlesion. Apamin binds with a higher affinity for SK2 than for SK3 channels (Finlayson et al., 2001; Grunnet et al., 2001). Others have found that the affinity of apamin for SK2 and SK3 is actually the same, but the ability of apamin to block SK2 is higher (Lamy et al., 2010). This might hide a potential decrease of channel protein at an earlier time-point.

We recently demonstrated that apamin given intraperitoneally between 15 to 25 days after similar striatal 6-OHDA infusions could counteract the motor and nonmotor symptoms (anxiety, anhedonia and visuospatial memory deficits) induced by partial dopaminergic striatal depletion (Chen et al., 2014). Apamin also increased extracellular DA concentration in the striatum of 6OHDA-lesioned rats (Chen et al., 2014). The present results show that apamin directly injected in the SNC at a dose of $0.2 \mathrm{ng}$ reduces the akinetic symptoms in the reaction time task produced by 
6-OHDA lesions. Interestingly, the SK channel positive modulator, CyPPA, while having no effect on its own, is able to counteract apamin action on RT performance when jointly administered with apamin into the SNC. SK3 channels appear to be specifically involved in this process as partial 6OHDA lesions only modulate SK3 channels mRNA expression and not SK2 channels. SK3 channels are known to control the timing and stability of the endogenous pacemaker activity of DA neurons in the SNC and VTA (Seutin et al., 1993; Wolfart et al., 2001) and to promote bursting in vivo (Waroux et al., 2005). Apamin administration increases DA neurotransmission in the nucleus accumbens (Herrik et al., 2012; Steketee and Kalivas, 1990). Altogether, these findings suggest that the blockade of SK channels in the spared midbrain DA neurons could compensate for the loss of DA activity in the dorsal striatum. Consistent with this hypothesis, the suppression of the endogenous SK currents in DA neurons by the expression of a mutant form of the human SK3 gene, increases burst firing by reducing the coupling between SK channels and N-methyl-Daspartate (NMDA) receptors, and ultimately enhances DA release (Soden et al., 2013).

\subsection{Upregulation of SK2 channels in the subthalamic nucleus}

In the subthalamic nucleus, 6-OHDA lesions of the nigrostriatal DA pathway produced a significant increase of SK2 mRNA expression and apamin binding sites that is correlated to the loss of THpositive cells at 21 days postlesion with no change at days 1 or 8 . SK3 mRNA expression was not modified at any time postlesion. The upregulation of SK2 channel expression in the STN is observed when a significant percentage of DA neurons degenerate in the SNC (37\%). Whether this upregulation is more pronounced over time when the DA neuronal degeneration progresses further still remains to be determined. Recent studies showed that 6-OHDA lesions induce an increase of firing rate, failures in autonomous activity, and pronounced burst activity in the STN (Park et al., 2015; Remple et al., 2011; Wilson et al., 2006; Zhu et al., 2002). A loss of around 40\% 
of TH-positive DA neurons is associated with an enhancement of bursting activity and change of STN neuronal firing pattern (Breit et al., 2007; Janssen et al., 2012; Park et al., 2015) consistent with data from Parkinsonian patients (Remple et al., 2011). The delayed onset of SK2 channel overexpression after 6-OHDA lesions of nigrostriatal DA neurons does not parallel the rapid disruption of DA transmission but rather correlates with homeostatic plasticity allowing neurons to compensate for perturbations in PD and chronic animal models (Azdad et al., 2009; Surmeier et al., 2007; Zigmond et al., 1990). In models of PD, variations of $\mathrm{K}$ channels expression are already considered as forms of homeostatic adaptation. Indeed, upregulation of KATP channels, in the prefrontal cortex and striatum, is found to serve as a protective mechanism after unilateral 6OHDA lesions of the SNC (Shen and Johnson, 2012; Wang et al., 2005). Inversely, decrease of a Kv4 channel-dependent $\mathrm{K}_{\mathrm{IA}}$ current in the striatal medium spiny neurons compensates for the reduction in glutamatergic efficiency after DA depletion (Azdad et al., 2009; Day et al., 2008, 2006). We previously showed that partial 6-OHDA lesions of nigrostriatal DA pathway leads to a dramatic increase in gene expression of the metabolic marker cytochrome oxidase subunit I (Col) mRNA in the STN (Oueslati et al., 2005). Abnormal activation of the STN may thus occur early in the course of the disease when striatal DA depletion is moderate as found here. Compared to previous data showing no or slight increase in Col mRNA expression in the STN after extensive striatal denervation (Vila et al., 2000), this suggests that STN reactivity may be even more pronounced at early than at later stages of the disease.

Consistent with this suggestion, apamin, when injected directly into the STN, dramatically enhances the akinetic symptoms in rats performing the RT task, presumably by enhancing subthalamic neuronal activity. Indeed, in vitro, addition of apamin on STN slices does not modify single-spike activity but increases irregular spike intervals and neuronal excitability (Hallworth et al., 2003; Wilson et al., 2004). These functional changes may explain the exacerbated deficits observed here. In contrast to apamin-induced effects, activating SK channels in the STN with the 
positive modulator CyPPA tended to reduce the motor impairment produced by 6-OHDA lesions. In vitro, activation of SK channels increases the amount and duration of single-spike afterhyperpolarization, which leads to a decrease in the frequency of autonomous rhythm. We may thus postulate that CyPPA could reverse the motor deficits produced by 6-OHDA lesions by decreasing the activity of STN neurons as previously found after STN lesions (Baunez et al., 1995). This remains to be investigated by recording subthalamic neurons in behaving animals.

The STN plays a central role in the response of the basal ganglia to cortical and thalamic activation during movement (Bevan et al., 2006). Taken together, these findings suggest that the variations of SK channels expression could reflect compensatory mechanisms occurring early in the progression of cellular defects in PD. The modulation of SK channels by activating SK2 subunits and/or blocking SK3 subunits with selective new compounds could thus be proposed as alternative therapeutic targets for the treatment of patients with Parkinson's disease.

\section{Funding and Disclosure}

The authors declare no conflict of interest. This work was supported by Aix Marseille University (AMU), within the context of the DHUNE project supported by $A^{*}$ MIDEX project (ANR-11-IDEX0001-02), the Centre National de la Recherche Scientifique (CNRS), Fondation de France and France Parkinson Association. The authors report no biomedical financial interests or potential conflicts of interest. 


\section{Acknowledgments}

The authors would like to thank Valérie Gilbert and Elodie Mansour for animal care, Isabelle Watabe and Didier Louber for technical assistance. 


\section{References}

Adelman, J.P., Maylie, J., Sah, P., 2012. Small-conductance Ca2+-activated K+ channels: form and function. Annu. Rev. Physiol. 74, 245-269. doi:10.1146/annurev-physiol-020911-153336

Aidi-Knani, S., Regaya, I., Amalric, M., Mourre, C., 2015. Kv4 channel blockade reduces motor and neuropsychiatric symptoms in rodent models of Parkinson's disease. Behav. Pharmacol. 26, 91-100. doi:10.1097/FBP.0000000000000107

Alvarez-Fischer, D., Noelker, C., Vulinović, F., Grünewald, A., Chevarin, C., Klein, C., Oertel, W.H., Hirsch, E.C., Michel, P.P., Hartmann, A., 2013. Bee venom and its component apamin as neuroprotective agents in a Parkinson disease mouse model. PloS One 8, e61700. doi:10.1371/journal.pone.0061700

Amalric, M., Moukhles, H., Nieoullon, A., Daszuta, A., 1995. Complex deficits on reaction time performance following bilateral intrastriatal 6-OHDA infusion in the rat. Eur. J. Neurosci. 7, 972-980.

Azdad, K., Chàvez, M., Don Bischop, P., Wetzelaer, P., Marescau, B., De Deyn, P.P., Gall, D., Schiffmann, S.N., 2009. Homeostatic plasticity of striatal neurons intrinsic excitability following dopamine depletion. PloS One 4, e6908. doi:10.1371/journal.pone.0006908

Baunez, C., Nieoullon, A., Amalric, M., 1995. In a rat model of parkinsonism, lesions of the subthalamic nucleus reverse increases of reaction time but induce a dramatic premature responding deficit. J. Neurosci. Off. J. Soc. Neurosci. 15, 6531-6541.

Bevan, M.D., Atherton, J.F., Baufreton, J., 2006. Cellular principles underlying normal and pathological activity in the subthalamic nucleus. Curr. Opin. Neurobiol. 16, 621-628. doi:10.1016/j.conb.2006.10.003

Blandini, F., Levandis, G., Bazzini, E., Nappi, G., Armentero, M.-T., 2007. Time-course of nigrostriatal damage, basal ganglia metabolic changes and behavioural alterations following intrastriatal injection of 6-hydroxydopamine in the rat: new clues from an old model. Eur. J. Neurosci. 25, 397-405. doi:10.1111/j.1460-9568.2006.05285.x

Bonito-Oliva, A., Masini, D., Fisone, G., 2014. A mouse model of non-motor symptoms in Parkinson's disease: focus on pharmacological interventions targeting affective dysfunctions. Front. Behav. Neurosci. 8, 290. doi:10.3389/fnbeh.2014.00290

Breit, S., Bouali-Benazzouz, R., Popa, R.C., Gasser, T., Benabid, A.L., Benazzouz, A., 2007. Effects of 6-hydroxydopamine-induced severe or partial lesion of the nigrostriatal pathway on the neuronal activity of pallido-subthalamic network in the rat. Exp. Neurol. 205, 36-47. doi:10.1016/j.expneurol.2006.12.016

Breysse, N., Baunez, C., Spooren, W., Gasparini, F., Amalric, M., 2002. Chronic but not acute treatment with a metabotropic glutamate 5 receptor antagonist reverses the akinetic deficits in a rat model of parkinsonism. J. Neurosci. Off. J. Soc. Neurosci. 22, 5669-5678. doi:20026513

Bustin, S.A., Benes, V., Garson, J.A., Hellemans, J., Huggett, J., Kubista, M., Mueller, R., Nolan, T., Pfaffl, M.W., Shipley, G.L., Vandesompele, J., Wittwer, C.T., 2009. The MIQE guidelines: minimum information for publication of quantitative real-time PCR experiments. Clin. Chem. 55, 611-622. doi:10.1373/clinchem.2008.112797

Chaudhuri, K.R., Odin, P., Antonini, A., Martinez-Martin, P., 2011. Parkinson's disease: the nonmotor issues. Parkinsonism Relat. Disord. 17, 717-723. doi:10.1016/j.parkreldis.2011.02.018

Chen, L., Deltheil, T., Turle-Lorenzo, N., Liberge, M., Rosier, C., Watabe, I., Sreng, L., Amalric, M., Mourre, C., 2014. SK channel blockade reverses cognitive and motor deficits induced by nigrostriatal dopamine lesions in rats. Int. J. Neuropsychopharmacol. Off. Sci. J. Coll. Int. Neuropsychopharmacol. CINP 17, 1295-1306. doi:10.1017/S1461145714000236 
Chergui, K., Suaud-Chagny, M.F., Gonon, F., 1994. Nonlinear relationship between impulse flow, dopamine release and dopamine elimination in the rat brain in vivo. Neuroscience 62, 641645.

Day, M., Wang, Z., Ding, J., An, X., Ingham, C.A., Shering, A.F., Wokosin, D., Ilijic, E., Sun, Z., Sampson, A.R., Mugnaini, E., Deutch, A.Y., Sesack, S.R., Arbuthnott, G.W., Surmeier, D.J., 2006. Selective elimination of glutamatergic synapses on striatopallidal neurons in Parkinson disease models. Nat. Neurosci. 9, 251-259. doi:10.1038/nn1632

Day, M., Wokosin, D., Plotkin, J.L., Tian, X., Surmeier, D.J., 2008. Differential excitability and modulation of striatal medium spiny neuron dendrites. J. Neurosci. Off. J. Soc. Neurosci. 28, 11603-11614. doi:10.1523/JNEUROSCI.1840-08.2008

Deignan, J., Luján, R., Bond, C., Riegel, A., Watanabe, M., Williams, J.T., Maylie, J., Adelman, J.P., 2012. SK2 and SK3 expression differentially affect firing frequency and precision in dopamine neurons. Neuroscience 217, 67-76. doi:10.1016/j.neuroscience.2012.04.053

Dolga, A.M., de Andrade, A., Meissner, L., Knaus, H.-G., Höllerhage, M., Christophersen, P., Zischka, H., Plesnila, N., Höglinger, G.U., Culmsee, C., 2014. Subcellular expression and neuroprotective effects of SK channels in human dopaminergic neurons. Cell Death Dis. 5, e999. doi:10.1038/cddis.2013.530

Evarts, E.V., Teräväinen, H., Calne, D.B., 1981. Reaction time in Parkinson's disease. Brain J. Neurol. 104, 167-186.

Finlayson, K., McLuckie, J., Hern, J., Aramori, I., Olverman, H.J., Kelly, J.S., 2001. Characterisation of [(125)I]-apamin binding sites in rat brain membranes with HE293 cells transfected with SK channel subtypes. Neuropharmacology 41, 341-350.

Grunnet, M., Jensen, B.S., Olesen, S.P., Klaerke, D.A., 2001. Apamin interacts with all subtypes of cloned small-conductance Ca2+-activated K+ channels. Pflüg. Arch. Eur. J. Physiol. 441, 544-550.

Hallworth, N.E., Wilson, C.J., Bevan, M.D., 2003. Apamin-sensitive small conductance calciumactivated potassium channels, through their selective coupling to voltage-gated calcium channels, are critical determinants of the precision, pace, and pattern of action potential generation in rat subthalamic nucleus neurons in vitro. J. Neurosci. Off. J. Soc. Neurosci. 23, $7525-7542$.

Herrik, K.F., Redrobe, J.P., Holst, D., Hougaard, C., Sandager-Nielsen, K., Nielsen, A.N., Ji, H., Holst, N.M., Rasmussen, H.B., Nielsen, E.Ø., Strøbæk, D., Shepard, P.D., Christophersen, P., 2012. CyPPA, a Positive SK3/SK2 Modulator, Reduces Activity of Dopaminergic Neurons, Inhibits Dopamine Release, and Counteracts Hyperdopaminergic Behaviors Induced by Methylphenidate. Front. Pharmacol. 3, 11. doi:10.3389/fphar.2012.00011

Hopf, F.W., Seif, T., Mohamedi, M.L., Chen, B.T., Bonci, A., 2010. The small-conductance calcium-activated potassium channel is a key modulator of firing and long-term depression in the dorsal striatum. Eur. J. Neurosci. 31, 1946-1959. doi:10.1111/j.14609568.2010.07231.x

Janssen, M.L.F., Zwartjes, D.G.M., Tan, S.K.H., Vlamings, R., Jahanshahi, A., Heida, T., Hoogland, G., Steinbusch, H.W.M., Visser-Vandewalle, V., Temel, Y., 2012. Mild dopaminergic lesions are accompanied by robust changes in subthalamic nucleus activity. Neurosci. Lett. 508, 101-105. doi:10.1016/j.neulet.2011.12.027

Köhler, M., Hirschberg, B., Bond, C.T., Kinzie, J.M., Marrion, N.V., Maylie, J., Adelman, J.P., 1996. Small-conductance, calcium-activated potassium channels from mammalian brain. Science 273, 1709-1714.

Lamy, C., Goodchild, S.J., Weatherall, K.L., Jane, D.E., Liégeois, J.-F., Seutin, V., Marrion, N.V., 2010. Allosteric block of KCa2 channels by apamin. J. Biol. Chem. 285, 27067-27077. doi:10.1074/jbc.M110.110072

Langnaese, K., John, R., Schweizer, H., Ebmeyer, U., Keilhoff, G., 2008. Selection of reference genes for quantitative real-time PCR in a rat asphyxial cardiac arrest model. BMC Mol. Biol. 9, 53. doi:10.1186/1471-2199-9-53 
Liu, X.-K., Wang, G., Chen, S.-D., 2010. Modulation of the activity of dopaminergic neurons by SK channels: a potential target for the treatment of Parkinson's disease? Neurosci. Bull. 26, 265-271.

Lopez, S., Jouve, L., Turle-Lorenzo, N., Kerkerian-Legoff, L., Salin, P., Amalric, M., 2012. Antiparkinsonian action of a selective group III mGlu receptor agonist is associated with reversal of subthalamonigral overactivity. Neurobiol. Dis. 46, 69-77. doi:10.1016/j.nbd.2011.12.045

Maneuf, Y.P., Duty, S., Hille, C.J., Crossman, A.R., Brotchie, J.M., 1996. Modulation of GABA transmission by diazoxide and cromakalim in the globus pallidus: implications for the treatment of Parkinson's disease. Exp. Neurol. 139, 12-16. doi:10.1006/exnr.1996.0075

Manrique, C., Compan, V., Rosselet, C., Duflo, S.G.D., 2009. Specific knock-down of GAD67 in the striatum using naked small interfering RNAs. J. Biotechnol. 142, 185-192. doi:10.1016/j.jbiotec.2009.05.009

Maurice, N., Deltheil, T., Melon, C., Degos, B., Mourre, C., Amalric, M., Kerkerian-Le Goff, L., 2015. Bee Venom Alleviates Motor Deficits and Modulates the Transfer of Cortical Information through the Basal Ganglia in Rat Models of Parkinson's Disease. PloS One 10, e0142838. doi:10.1371/journal.pone.0142838

McGeer, P.L., Itagaki, S., Akiyama, H., McGeer, E.G., 1988. Rate of cell death in parkinsonism indicates active neuropathological process. Ann. Neurol. 24, 574-576. doi:10.1002/ana.410240415

Mourre, C., Hugues, M., Lazdunski, M., 1986. Quantitative autoradiographic mapping in rat brain of the receptor of apamin, a polypeptide toxin specific for one class of $\mathrm{Ca} 2+$-dependent $\mathrm{K}+$ channels. Brain Res. 382, 239-49.

Mpari, B., Sreng, L., Regaya, I., Mourre, C., 2008. Small-conductance Ca(2+)-activated K(+) channels: Heterogeneous affinity in rat brain structures and cognitive modulation by specific blockers. Eur. J. Pharmacol. 589, 140-8. doi:10.1016/j.ejphar.2008.05.019

Nelissen, K., Smeets, K., Mulder, M., Hendriks, J.J.A., Ameloot, M., 2010. Selection of reference genes for gene expression studies in rat oligodendrocytes using quantitative real time PCR. J. Neurosci. Methods 187, 78-83. doi:10.1016/j.jneumeth.2009.12.018

Oueslati, A., Breysse, N., Amalric, M., Kerkerian-Le Goff, L., Salin, P., 2005. Dysfunction of the cortico-basal ganglia-cortical loop in a rat model of early parkinsonism is reversed by metabotropic glutamate receptor 5 antagonism. Eur. J. Neurosci. 22, 2765-2774. doi:10.1111/j.1460-9568.2005.04498.x

Park, S.E., Song, K.-I., Suh, J.-K.F., Hwang, D., Youn, I., 2015. A time-course study of behavioral and electrophysiological characteristics in a mouse model of different stages of Parkinson's disease using 6-hydroxydopamine. Behav. Brain Res. 284, 153-157. doi:10.1016/j.bbr.2015.02.019

Paxinos G and Watson C, 2007. The Rat Brain in Stereotaxic Coordinates, Elsevier Academic Press. ed. Amsterdam.

Pedarzani, P., Stocker, M., 2008. Molecular and cellular basis of small--and intermediateconductance, calcium-activated potassium channel function in the brain. Cell. Mol. Life Sci. CMLS 65, 3196-3217. doi:10.1007/s00018-008-8216-x

Pongs, O., 2008. Regulation of excitability by potassium channels. Results Probl. Cell Differ. 44, 145-161. doi:10.1007/400_2007_032

Remple, M.S., Bradenham, C.H., Kao, C.C., Charles, P.D., Neimat, J.S., Konrad, P.E., 2011. Subthalamic nucleus neuronal firing rate increases with Parkinson's disease progression. Mov. Disord. Off. J. Mov. Disord. Soc. 26, 1657-1662. doi:10.1002/mds.23708

Rosenblad, C., Kirik, D., Björklund, A., 2000. Sequential administration of GDNF into the substantia nigra and striatum promotes dopamine neuron survival and axonal sprouting but not striatal reinnervation or functional recovery in the partial 6-OHDA lesion model. Exp. Neurol. 161, 503-516. doi:10.1006/exnr.1999.7296 
Sailer, C.A., Kaufmann, W.A., Marksteiner, J., Knaus, H.-G., 2004. Comparative immunohistochemical distribution of three small-conductance $\mathrm{Ca} 2+$-activated potassium channel subunits, SK1, SK2, and SK3 in mouse brain. Mol. Cell. Neurosci. 26, 458-69. doi: 15234350

Salthun-Lassalle, B., Hirsch, E.C., Wolfart, J., Ruberg, M., Michel, P.P., 2004. Rescue of mesencephalic dopaminergic neurons in culture by low-level stimulation of voltage-gated sodium channels. J. Neurosci. Off. J. Soc. Neurosci. 24, 5922-5930. doi:10.1523/JNEUROSCI.5668-03.2004

Schiemann, J., Schlaudraff, F., Klose, V., Bingmer, M., Seino, S., Magill, P.J., Zaghloul, K.A., Schneider, G., Liss, B., Roeper, J., 2012. K-ATP channels in dopamine substantia nigra neurons control bursting and novelty-induced exploration. Nat. Neurosci. 15, 1272-1280. doi: $10.1038 / \mathrm{nn} .3185$

Schultz, W., 2002. Getting formal with dopamine and reward. Neuron 36, 241-263.

Seutin, V., Johnson, S.W., North, R.A., 1993. Apamin increases NMDA-induced burst-firing of rat mesencephalic dopamine neurons. Brain Res. 630, 341-344.

Shen, K.-Z., Johnson, S.W., 2012. Chronic dopamine depletion augments the functional expression of K-ATP channels in the rat subthalamic nucleus. Neurosci. Lett. 531, 104-108. doi:10.1016/j.neulet.2012.10.030

Soden, M.E., Jones, G.L., Sanford, C.A., Chung, A.S., Güler, A.D., Chavkin, C., Luján, R., Zweifel, L.S., 2013. Disruption of dopamine neuron activity pattern regulation through selective expression of a human KCNN3 mutation. Neuron 80, 997-1009. doi:10.1016/j.neuron.2013.07.044

Steketee, J.D., Kalivas, P.W., 1990. Effect of microinjections of apamin into the A10 dopamine region of rats: a behavioral and neurochemical analysis. J. Pharmacol. Exp. Ther. 254, 711719.

Stocker, M., Krause, M., Pedarzani, P., 1999. An apamin-sensitive Ca2+-activated K+ current in hippocampal pyramidal neurons. Proc. Natl. Acad. Sci. U. S. A. 96, 4662-7. doi:10200319

Stocker, M., Pedarzani, P., 2000. Differential distribution of three $\mathrm{Ca}(2+)$-activated $\mathrm{K}(+)$ channel subunits, SK1, SK2, and SK3, in the adult rat central nervous system. Mol. Cell. Neurosci. 15, 476-93. doi:10833304

Stott, S.R.W., Barker, R.A., 2014. Time course of dopamine neuron loss and glial response in the 6OHDA striatal mouse model of Parkinson's disease. Eur. J. Neurosci. 39, 1042-1056. doi:10.1111/ejn.12459

Surmeier, D.J., Ding, J., Day, M., Wang, Z., Shen, W., 2007. D1 and D2 dopamine-receptor modulation of striatal glutamatergic signaling in striatal medium spiny neurons. Trends Neurosci. 30, 228-235. doi:10.1016/j.tins.2007.03.008

Tadaiesky, M.T., Dombrowski, P.A., Figueiredo, C.P., Cargnin-Ferreira, E., Da Cunha, C., Takahashi, R.N., 2008. Emotional, cognitive and neurochemical alterations in a premotor stage model of Parkinson's disease. Neuroscience 156, 830-840. doi:10.1016/j.neuroscience.2008.08.035

Vila, M., Périer, C., Féger, J., Yelnik, J., Faucheux, B., Ruberg, M., Raisman-Vozari, R., Agid, Y., Hirsch, E.C., 2000. Evolution of changes in neuronal activity in the subthalamic nucleus of rats with unilateral lesion of the substantia nigra assessed by metabolic and electrophysiological measurements. Eur. J. Neurosci. 12, 337-344.

Wang, S., Hu, L.-F., Yang, Y., Ding, J.-H., Hu, G., 2005. Studies of ATP-sensitive potassium channels on 6-hydroxydopamine and haloperidol rat models of Parkinson's disease: implications for treating Parkinson's disease? Neuropharmacology 48, 984-992. doi:10.1016/j.neuropharm.2005.01.009

Wang, Y., Yang, P., Tang, J., Lin, J., Cai, X., Wang, X., Zheng, G., 2008. Potassium channels: possible new therapeutic targets in Parkinson's disease. Med. Hypotheses 71, 546-550. doi:10.1016/j.mehy.2008.05.021 
Waroux, O., Massotte, L., Alleva, L., Graulich, A., Thomas, E., Liégeois, J.-F., Scuvée-Moreau, J., Seutin, V., 2005. SK channels control the firing pattern of midbrain dopaminergic neurons in vivo. Eur. J. Neurosci. 22, 3111-3121. doi:10.1111/j.1460-9568.2005.04484.x

Wilson, C.L., Cash, D., Galley, K., Chapman, H., Lacey, M.G., Stanford, I.M., 2006. Subthalamic nucleus neurones in slices from 1-methyl-4-phenyl-1,2,3,6-tetrahydropyridine-lesioned mice show irregular, dopamine-reversible firing pattern changes, but without synchronous activity. Neuroscience 143, 565-572. doi:10.1016/j.neuroscience.2006.07.051

Wilson, C.L., Puntis, M., Lacey, M.G., 2004. Overwhelmingly asynchronous firing of rat subthalamic nucleus neurones in brain slices provides little evidence for intrinsic interconnectivity. Neuroscience 123, 187-200.

Wolfart, J., Neuhoff, H., Franz, O., Roeper, J., 2001. Differential expression of the smallconductance, calcium-activated potassium channel SK3 is critical for pacemaker control in dopaminergic midbrain neurons. J. Neurosci. Off. J. Soc. Neurosci. 21, 3443-3456.

Zhu, Z., Bartol, M., Shen, K., Johnson, S.W., 2002. Excitatory effects of dopamine on subthalamic nucleus neurons: in vitro study of rats pretreated with 6-hydroxydopamine and levodopa. Brain Res. 945, 31-40.

Zigmond, M.J., Abercrombie, E.D., Berger, T.W., Grace, A.A., Stricker, E.M., 1990. Compensations after lesions of central dopaminergic neurons: some clinical and basic implications. Trends Neurosci. 13, 290-296. 


\section{Captions}

\section{Figure 1}

Evaluation of 6-OHDA lesion extent. A: Tyrosine hydroxylase (TH) immunohistochemistry. Representative illustrations of TH immunostaining in the substantia nigra pars compacta (SNC) at 21 days after a bilateral intrastriatal injection of 6 -hydroxydopamine $(6-O H D A, n=1)$ or vehicle (sham, $\mathrm{n}=1$ ). A substantial loss of $\mathrm{TH}$-immunoreactive cells was observed at different rostro-caudal levels of the SNC (-5.04 to $-5.76 \mathrm{~mm}$ according to bregma) in a 6-OHDA-lesioned rat. SNR, substantia nigra pars reticulata; VTA, ventral tegmental area. Scale bar: $500 \mu \mathrm{m}$. B: Number of THpositive cells by coronal section at different rostro-caudal levels in the SNC of 6-OHDA-lesioned animals at 1,8 or 21 days postlesion ( $n=8,7$ and 8 , respectively) compared with sham animals $(n=$ 8,8 and 8 , respectively). Data are expressed as mean \pm S.E.M., ANOVA, $* P<0.05$ compared to sham groups, \# P<0.05 compared to 6-OHDA-lesioned groups. C: Mazindol binding. Illustrative autoradiographs of $\left[{ }^{3} \mathrm{H}\right]$-mazindol binding to dopamine uptake sites in the striatum at different rostro-caudal levels (1.68 to -1.44 according to bregma), at 21 days after bilateral 6-OHDA lesions. In the caudate putamen $(\mathrm{CPu})$, the lesioned area was defined by a loss of dopamine uptake binding sites (in light gray) compared to the intact area (dark gray). There was no loss of mazindol binding in the accumbens nucleus (Acb). Scale bar: $3 \mathrm{~mm}$. D: Mazindol binding site levels in the striatum expressed as the ratio of the lesioned area over the total striatal area ( $n=8 /$ group). E: Correlation between the number of TH-positive cells by sections in the SNC and the mazindol binding levels. Simple-linear regression analyses. Each dot represents data of one subject. Dotted lines correspond to the $95 \%$ confidence of regression line. Note the negative correlation between mazindol binding sites levels in the lesioned area and the number of TH-positive cells by sections in the SNC. 


\section{Figure 2}

Expression of SK channels in the rat substantia nigra and subthalamic nucleus of sham and 6OHDA-lesioned rats at 21 days postlesion. A: Histological reconstructions of sections, indicating the location of the substantia nigra, pars compacta (SNC) (left) and of the subthalamic nucleus (STN) (right), adapted from Paxinos and Watson (2007). B: Representative distribution of apamin binding sites; Coronal brain sections were incubated with [ $\left.{ }^{125} \mathrm{I}\right]$-apamin (25 pM). The dark areas indicated high staining intensity, corresponding to a high density of binding sites. Note that apamin binding sites decreased in SNC and increased in STN, 21 days after the 6-OHDA lesions; In situ hybridization of SK2 mRNA (C) or SK3 mRNA (D). SK2 and SK3 mRNA signals were revealed by autoradiographic in situ hybridization using a specific antisense probe labeled with $\left[{ }^{35} \mathrm{~S}\right]$. Note that SK3 mRNA expression were reduced in the SNC and SK2 mRNA expression enhanced in the STN 21 days after 6-OHDA lesions. Bar $=1 \mathrm{~mm}$.

\section{Figure 3}

Expression of SK channels in the substantia nigra, pars compacta at 21 days postlesion. Left: (A) Levels of apamin binding sites in sham $(n=8)$ and 6-OHDA-lesioned groups $(n=8)$. (B) ISH, levels of SK2 mRNA. (C) ISH, levels of SK3 mRNA. (D) qRT-PCR, quantitative mRNA expression for the three genes encoding the SK2 and SK3 subunits and the dopamine transporter (DAT) in 6-OHDA-lesioned group ( $n=11$, bar graphs) in comparison to sham group ( $n=10$, dotted line). Note the decrease of apamin binding level and of SK3 mRNA expression level in 6-OHDA-lesioned group. Right: Correlation between the number of TH-positive cells in the SNC and the apamin binding site density or SK channel mRNA levels. Simple-linear regression analysis. Each dot corresponds to the data of one 6-OHDA-lesioned subject. Dotted lines correspond to the $95 \%$ confidence of 
regression line. Note the positive direction of correlation for apamin binding sites and SK3 mRNA levels but not with SK2 mRNA levels. The SK3 channel expression decreased in correlation with dopamine degeneration since SK2 channels expression did not differ. Data expressed as mean \pm S.E.M. ${ }^{*} \mathrm{P}<0.05$, statistical significance between sham and 6-OHDA groups.

\section{Figure 4}

Expression of SK channels in the subthalamic nucleus at 21 days postlesion. Left: (A) Levels of apamin binding sites in sham $(n=8)$ and 6-OHDA-lesioned groups $(n=8)$. (B) ISH, levels of SK2 mRNA. (C) ISH, levels of SK3 mRNA. (D) qRT-PCR, quantitative mRNA expression for the three genes encoding the SK2 and SK3 subunits and the dopamine transporter (DAT) in 6-OHDA-lesioned group ( $n=11$, bar graphs) in comparison to sham group ( $n=10$, dotted line). Note the increase of apamin binding level and of SK2 mRNA expression in 6-OHDA-lesioned group. Right: Correlation between the number of TH-positive cells in the SNC and the apamin binding site density or SK channel mRNA levels. Simple-linear regression analysis. Each dot corresponds to the data of one 6OHDA-lesioned subject. Dotted lines correspond to the $95 \%$ confidence of regression line. Note the negative correlation for apamin binding sites and SK2 mRNA levels but not with SK3 mRNA levels. The SK2 channel expression increased with dopamine degeneration since SK3 channels expression did not differ. Data expressed as mean \pm S.E.M. ${ }^{*} P<0.05$, statistical significance between sham and 6-OHDA groups.

\section{Figure 5}

Behavioral effects of the SK channel modulation in 6-OHDA-lesioned animals on reaction time performance. Performance is expressed by the mean number of incorrect responses (delayed response over the time limit of $600 \mathrm{~ms}) \pm$ S.E.M. SK channel blockade or activation was performed 
respectively by apamin or CyPPa infusion in the substantia nigra (SN) (A) or in the subthalamic nucleus (STN) (B) of sham ( $n=7$ and 13 respectively, open bars) and of 6-OHDA-lesioned ( $n=7$ and 16 respectively, black bars) groups. Note the increase of incorrect responses after lesion in the 6-OHDA groups compared to sham groups. Apamin (0.2 ng) infusion in the SNC of 6-OHDAlesioned groups reduced the akinetic deficit that was counteracted by a simultaneous infusion of the SK channel positive modulator (CyPPa, $0.1 \mu \mathrm{g})$. Inversely, apamin $(0.1 \mathrm{ng})$ infusion in the STN of 6-OHDA-lesioned groups increased the number of incorrect responses while CyPPa (0.1 $\mu \mathrm{g})$ administration reduced the akinetic deficit. ANOVA, * $\mathrm{P}<0.05$ compared to sham groups, \# $\mathrm{P}<0.05$ compared to vehicle-injected 6-OHDA group.

\section{Supplemental data}

Table S1: Gene-specific primers used for qRT-PCR

\section{Figure S1}

Representations of the placements of the injector needles in the substantia nigra and subthalamic nucleus. Photomicrographs of one representative section from two subjects depicting bilateral cannula tracks (arrows) with tips located in the substantia nigra, pars compacta (SNC) or in the subthalamic nucleus (STN). Dashed lines mark the SNC, SNR (substantia nigra, pars reticulata), and $\mathrm{cp}$ (cerebral peduncle) on the left, and the STN and $\mathrm{cp}$ on the right. (B) Frontal sections of brain showing histological reconstruction of injection sites in the SNC $(n=12)$ and STN $(n=19)$. Values give the distance in $\mathrm{mm}$ from bregma according to the atlas of Paxinos and Watson (2007). Bar $=2 \mathrm{~mm}$. 


\section{Figure S2}

Expression of SK3 channels in the substantia nigra, pars compacta at 1 (A) and 8 (B) days postlesion. Left: Levels of SK3 mRNA. Note the decrease of apamin binding level and of SK3 mRNA density in 6-OHDA-lesioned group. Right: Correlation between the number of TH-positive cells in the SNC and SK3 channel mRNA levels. Simple-linear regression analysis. Each point corresponded to the data of one 6-OHDA-lesioned rat. Dotted lines correspond to the $95 \%$ confidence of regression line. Note the positive correlation for apamin binding sites and SK3 mRNA levels. Data expressed as mean \pm S.E.M. ${ }^{*} P<0.05$, statistical significance between sham and 6-OHDA groups.

\section{Figure S3}

Behavioral effects of SK channel blockade with apamin injected in the substantia nigra of sham $(n=8)$ and 6-OHDA-lesioned $(n=12)$ animals on reaction time performance. Performance is expressed by the mean number of incorrect responses (delayed response over the time limit of $600 \mathrm{~ms}) \pm$ S.E.M.. Note the increase of incorrect responses after lesion in the 6-OHDA-lesioned groups compared to sham groups. Apamin at a dose of $0.2 \mathrm{ng}$ but not at $0.1 \mathrm{ng}$ reduced the number of delayed responses to reach the level of performance of sham groups. ANOVA, $* P<0.05$ compared to sham groups.

\section{Figure S4}

Behavioral effects of the vehicle injections at the same postoperative days than apamin or CyPPa administration on reaction time performance. Performance is expressed by the mean number of incorrect responses (delayed response over the time limit of $600 \mathrm{~ms}) \pm$ S.E.M. in the sham $(n=7)$ and 6-OHDA-lesioned $(n=6)$ groups. There was no significant difference on behavioral performance of the two groups over time. 


\begin{tabular}{|c|c|c|c|c|c|c|}
\hline & \multicolumn{2}{|c|}{ Apamin binding sites } & \multicolumn{2}{|c|}{ SK2 mRNA } & \multicolumn{2}{|c|}{ SK3 mRNA } \\
\hline & Sham & 6-OHDA & Sham & 6-OHDA & Sham & 6-OHDA \\
\hline \multicolumn{7}{|l|}{ D1 } \\
\hline Caudate putamen & $229.83 \pm 1.90$ & $222.91 \pm 4.55$ & $39.84 \pm 1.82$ & $44.86 \pm 1.98$ & $56.69 \pm 9.47$ & $74.48 \pm 7.24$ \\
\hline Accumbens nucleus & $270.34 \pm 4.16$ & $289.72 \pm 5.55$ & $38.02 \pm 3.63$ & $42.95 \pm 1.86$ & $101.74 \pm 7.23$ & $100.57 \pm 7.18$ \\
\hline Globus pallidus & $118.96 \pm 8.87$ & $119.18 \pm 6.59$ & $31.00 \pm 2.35$ & $32.39 \pm 2.37$ & $42.47 \pm 5.73$ & $39.30 \pm 3.85$ \\
\hline Entopeduncular nucleus & $89.76 \pm 5.63$ & $89.65 \pm 5.01$ & $36.38 \pm 1.43$ & $39.41 \pm 2.54$ & $84.57 \pm 3.95$ & $75.32 \pm 4.57$ \\
\hline Subthalamic nucleus & $131.88 \pm 4.88$ & $140.28 \pm 5.31$ & $109.58 \pm 3.81$ & $105.86 \pm 5.62$ & $40.59 \pm 1.38$ & $42.29 \pm 2.16$ \\
\hline Substantia nigra, pars compacta & $186.36 \pm 8.41$ & $181.22 \pm 7.01$ & $88.39 \pm 5.05$ & $92.66 \pm 5.66$ & $151.76 \pm 6.02$ & $108.49 \pm 5.67^{\star}$ \\
\hline Substantia nigra, pars reticulata & $150.03 \pm 7.96$ & $145.74 \pm 5.99$ & $45.60 \pm 4.47$ & $49.64 \pm 4.45$ & $43.96 \pm 4.17$ & $33.26 \pm 2.46$ \\
\hline \multirow[t]{2}{*}{ Ventral tegmental area } & $171.11 \pm 7.37$ & $176.80 \pm 8.87$ & $82.16 \pm 8.92$ & $93.74 \pm 8.97$ & $104.87 \pm 9.73$ & $84.44 \pm 4.20$ \\
\hline & \multicolumn{6}{|c|}{ 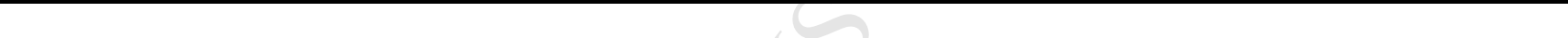 } \\
\hline \multicolumn{7}{|l|}{ D8 } \\
\hline Caudate putamen & $239.11 \pm 6.59$ & $243.36 \pm 2.14$ & $42.01 \pm 4.44$ & $46.34 \pm 4.87$ & $73.11 \pm 6.88$ & $70.74 \pm 5.77$ \\
\hline Accumbens nucleus & $287.14 \pm 3.71$ & $285.28 \pm 5.03$ & $43.64 \pm 5.54$ & $39.88 \pm 4.09$ & $93.60 \pm 7.13$ & $107.96 \pm 8.97$ \\
\hline Globus pallidus & $111.74 \pm 5.32$ & $115.92 \pm 4.09$ & $27.77 \pm 1.65$ & $28.99 \pm 1.28$ & $43.10 \pm 5.95$ & $37.57 \pm 2.80$ \\
\hline Entopeduncular nucleus & $97.94 \pm 4.19$ & $100.34 \pm 4.78$ & $39.63 \pm 3.59$ & $36.47 \pm 2.58$ & $82.13 \pm 4.39$ & $76.00 \pm 5.74$ \\
\hline Subthalamic nucleus & $120.27 \pm 11.77$ & $135.64 \pm 7.69$ & $117.88 \pm 7.75$ & $109.60 \pm 4.21$ & $45.68 \pm 2.53$ & $41.55 \pm 5.16$ \\
\hline Substantia nigra, pars compacta & $201.66 \pm 6.82$ & $198.94 \pm 3.24$ & $99.08 \pm 5.78$ & $84.70 \pm 5.94$ & $141.67 \pm 4.61$ & $107.82 \pm 8.19^{\star}$ \\
\hline Substantia nigra, pars reticulata & $161.76 \pm 5.16$ & $166.55 \pm 3.57$ & $52.19 \pm 2.90$ & $51.29 \pm 5.82$ & $35.92 \pm 2.20$ & $34.43 \pm 2.77$ \\
\hline Ventral tegmental area & $177.34 \pm 3.71$ & $179.11 \pm 3.55$ & $87.25 \pm 6.09$ & $85.04 \pm 11.54$ & $100.79 \pm 5.87$ & $88.44 \pm 5.83$ \\
\hline \multicolumn{7}{|l|}{$\overline{D 21}$} \\
\hline Caudate putamen & $237.12 \pm 4.19$ & $236.69 \pm 3.22$ & $42.91 \pm 5.02$ & $41.40 \pm 5.53$ & $75.57 \pm 4.06$ & $75.03 \pm 6.56$ \\
\hline Accumbens nucleus & $279.05 \pm 3.39$ & $281.23 \pm 2.50$ & $43.61 \pm 4.76$ & $46.02 \pm 4.49$ & $103.13 \pm 6.96$ & $114.52 \pm 11.05$ \\
\hline Globus pallidus & $106.67 \pm 4.97$ & $112.60 \pm 2.92$ & $30.12 \pm 2.11$ & $27.89 \pm 1.33$ & $41.08 \pm 3.28$ & $38.11 \pm 4.21$ \\
\hline Entopeduncular nucleus & $97.35 \pm 4.14$ & $97.47 \pm 4.24$ & $37.87 \pm 2.39$ & $38.80 \pm 3.40$ & $82.13 \pm 3.04$ & $70.77 \pm 3.73$ \\
\hline Subthalamic nucleus & $147.40 \pm 2.72$ & $168.66 \pm 3.06^{\star}$ & $112.44 \pm 1.43$ & $132.69 \pm 2.27^{\star}$ & $44.59 \pm 3.45$ & $46.49 \pm 1.71$ \\
\hline Substantia nigra, pars compacta & $184.03 \pm 3.18$ & $161.78 \pm 5.81^{*}$ & $87.21 \pm 10.21$ & $78.66 \pm 6.88$ & $133.53 \pm 9.76$ & $78.83 \pm 11.07^{\star}$ \\
\hline Substantia nigra, pars reticulata & $146.84 \pm 5.89$ & $156.66 \pm 6.13$ & $47.23 \pm 5.63$ & $50.02 \pm 5.38$ & $38.82 \pm 4.15$ & $31.14 \pm 3.10$ \\
\hline Ventral tegmental area & $165.26 \pm 9.42$ & $165.81 \pm 5.94$ & $82.74 \pm 10.38$ & $91.90 \pm 4.30$ & $100.07 \pm 4.43$ & $78.45 \pm 7.19^{*}$ \\
\hline
\end{tabular}

Values are mean \pm S.E.M.

ANOVA, Tukey post hoc test, ${ }^{*} P<0.05$ 


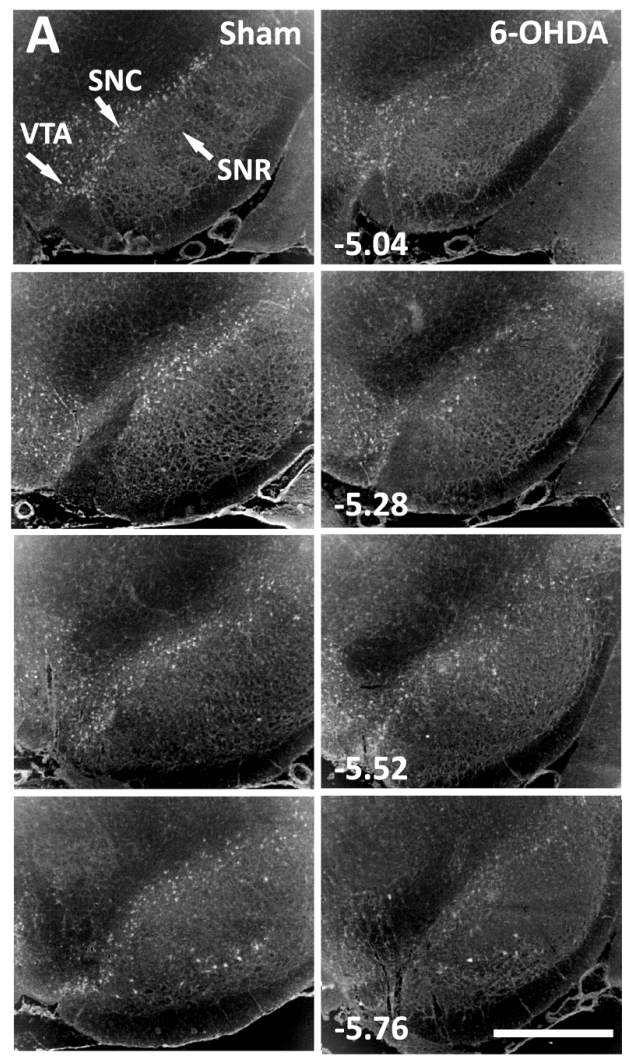

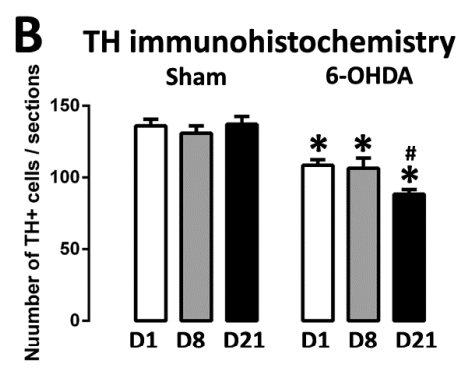

C

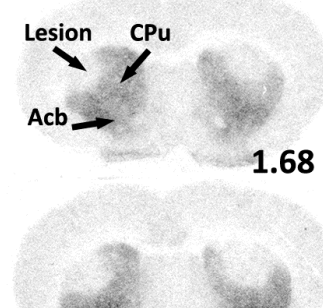

1.28

D ${ }^{50}{ }_{6-\mathrm{OHDA}}$ Mazindol binding

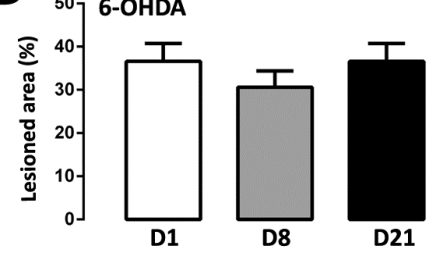

E $\left.\quad{ }^{60}\right]^{D 21}$

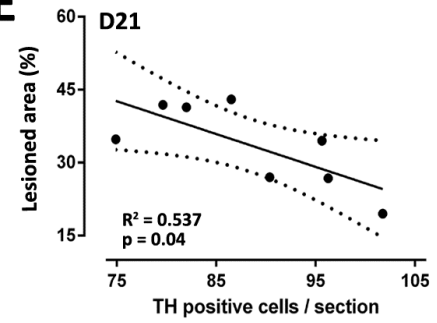

$-0.36$

$-1.44$ 
A

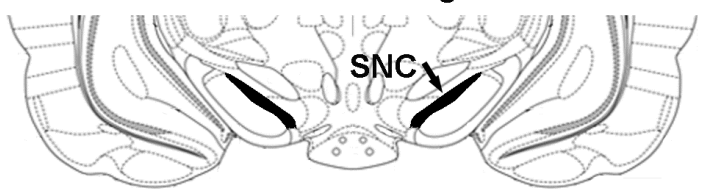

Subthalamic nucleus

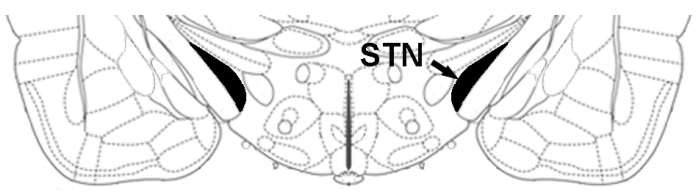

\section{B Apamin binding sites}
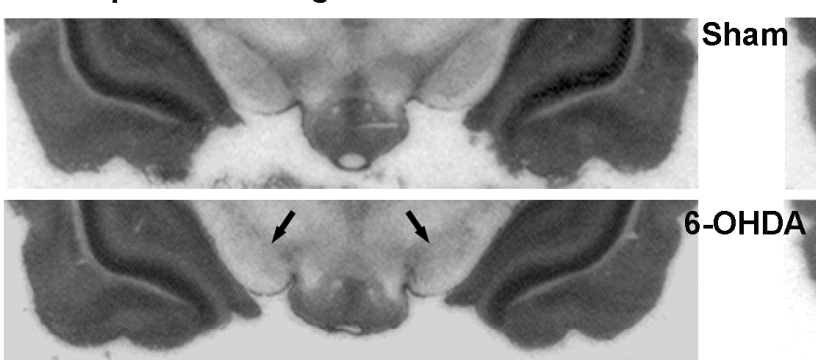

C SK2 mRNA
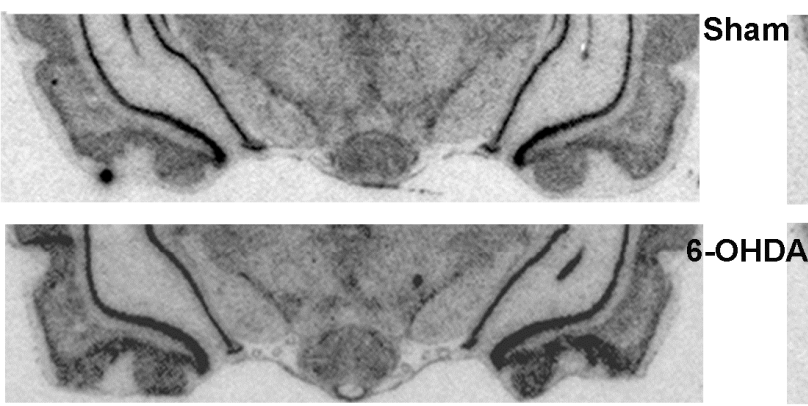

D SK3 mRNA

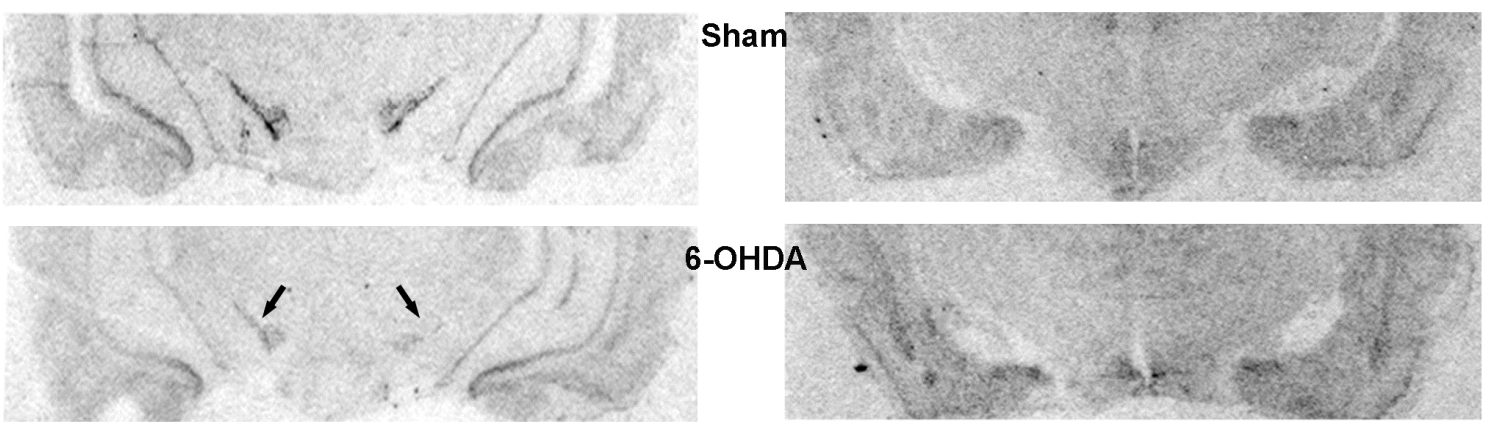

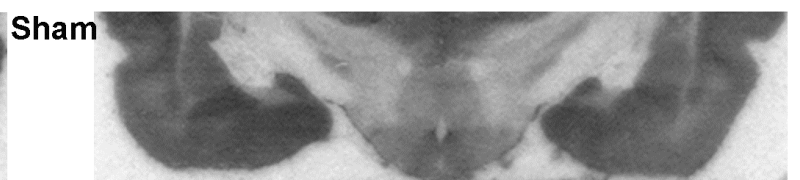
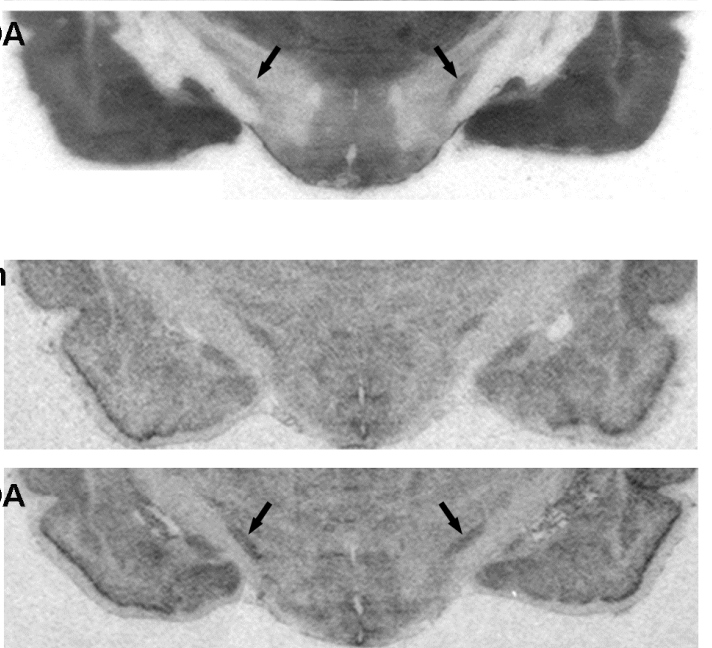


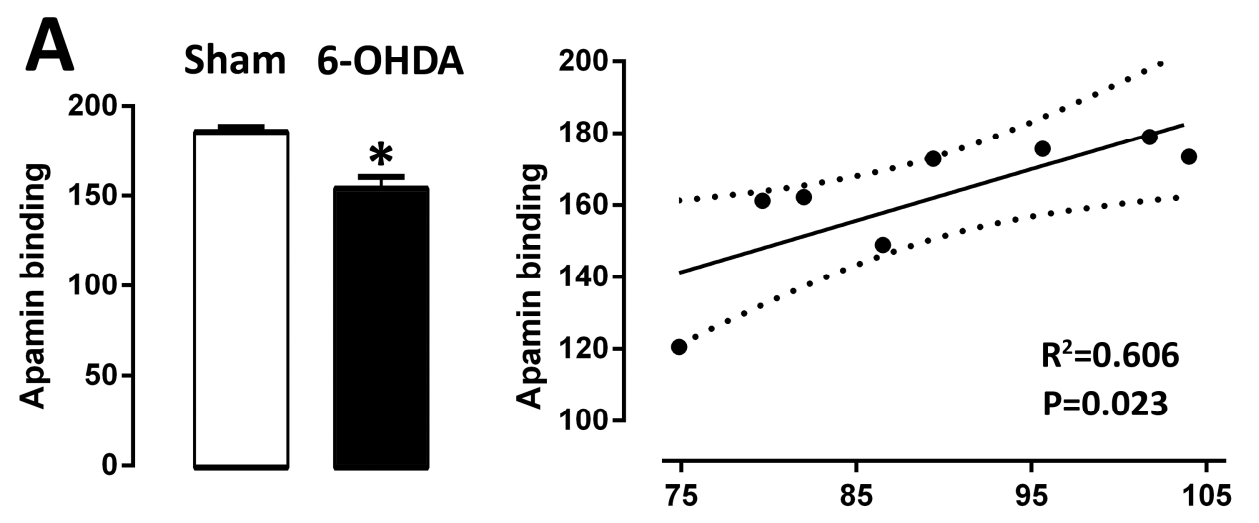

B
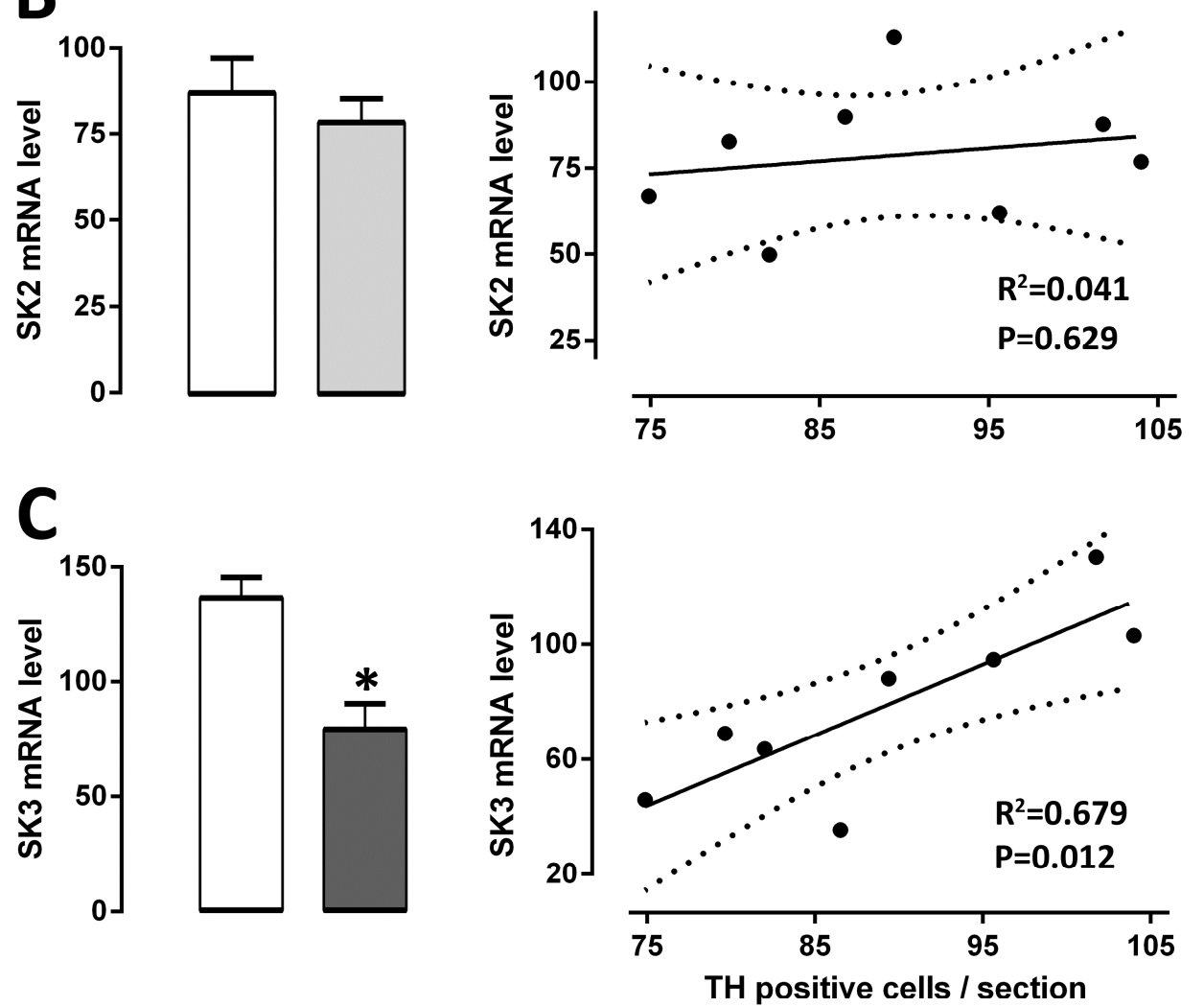

D
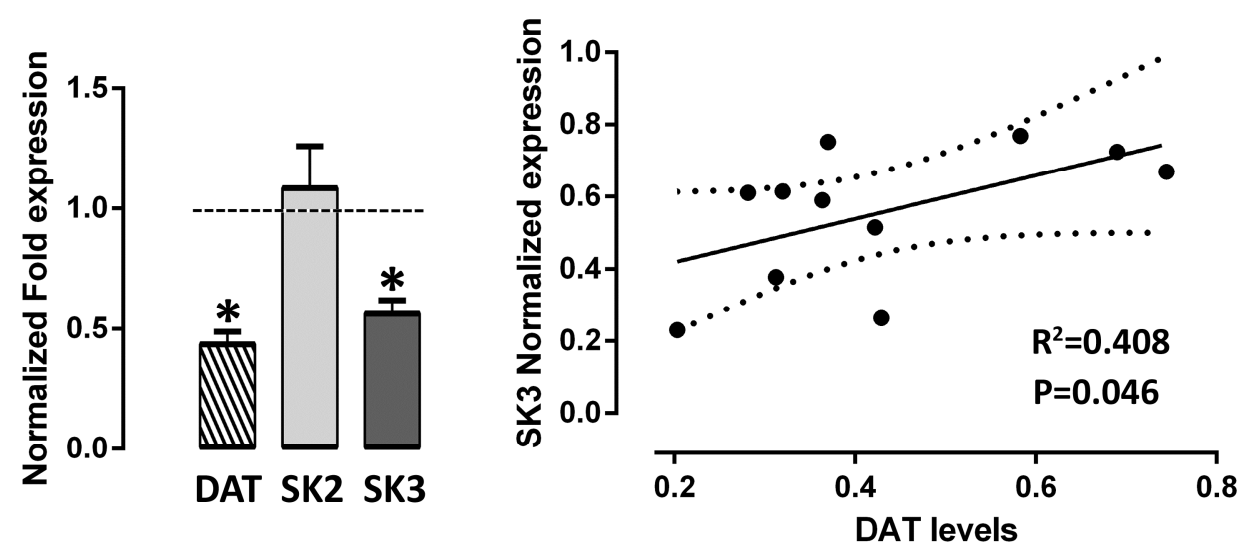
A

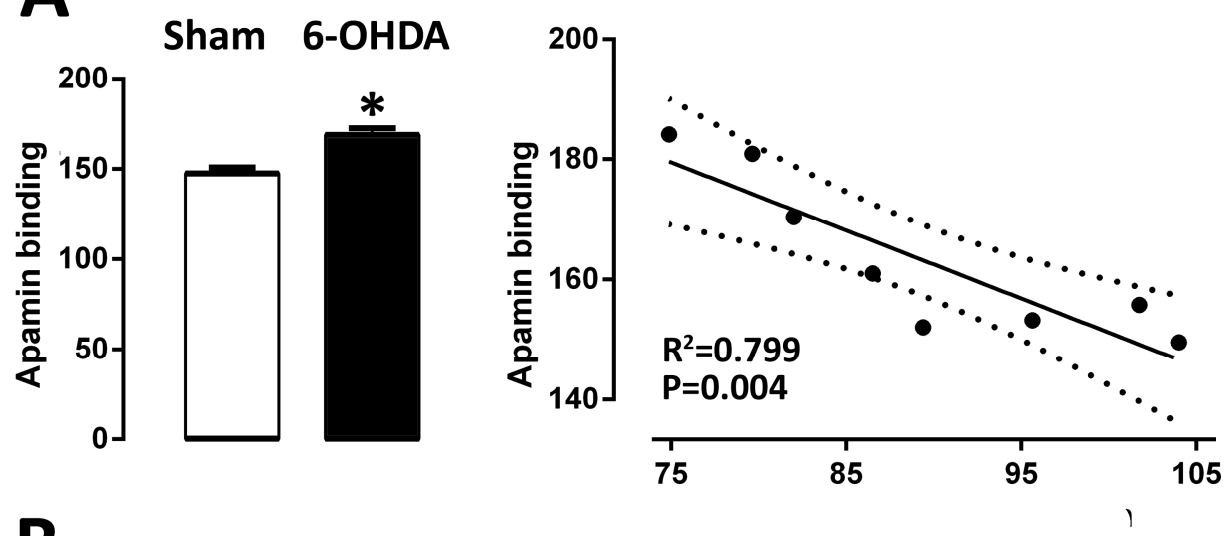

B
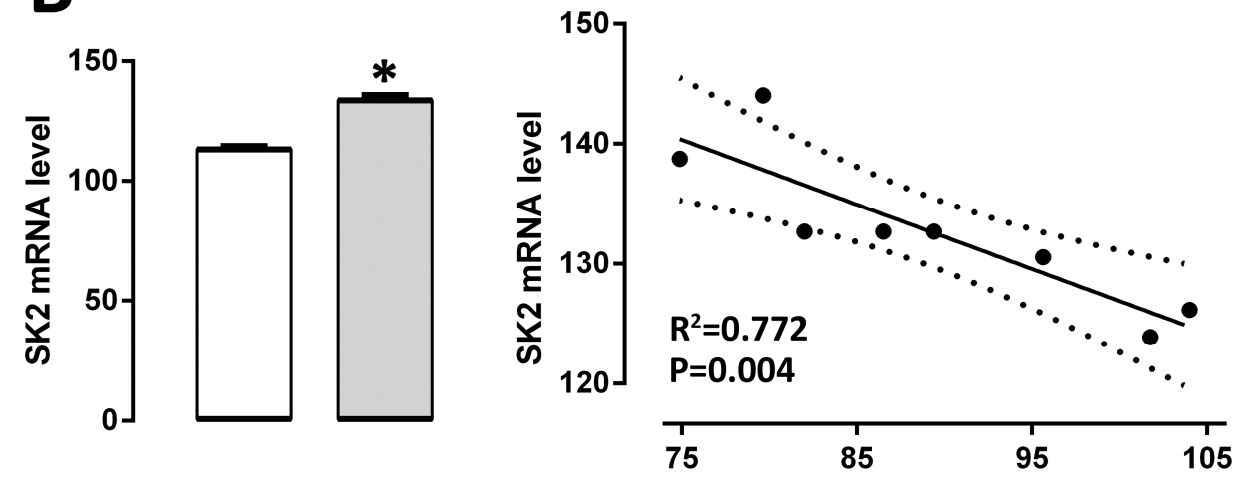

C
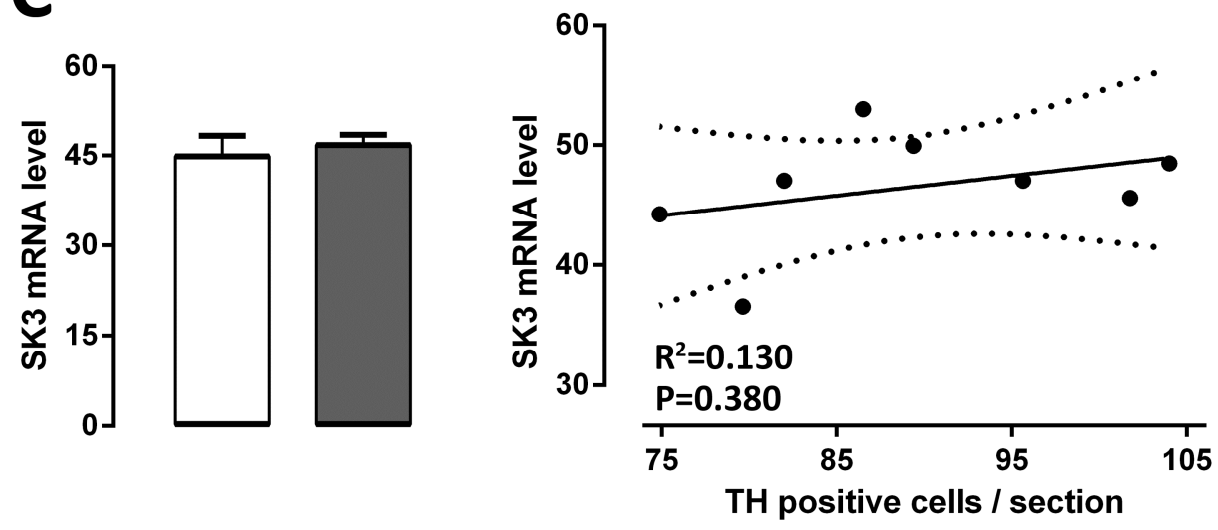

D
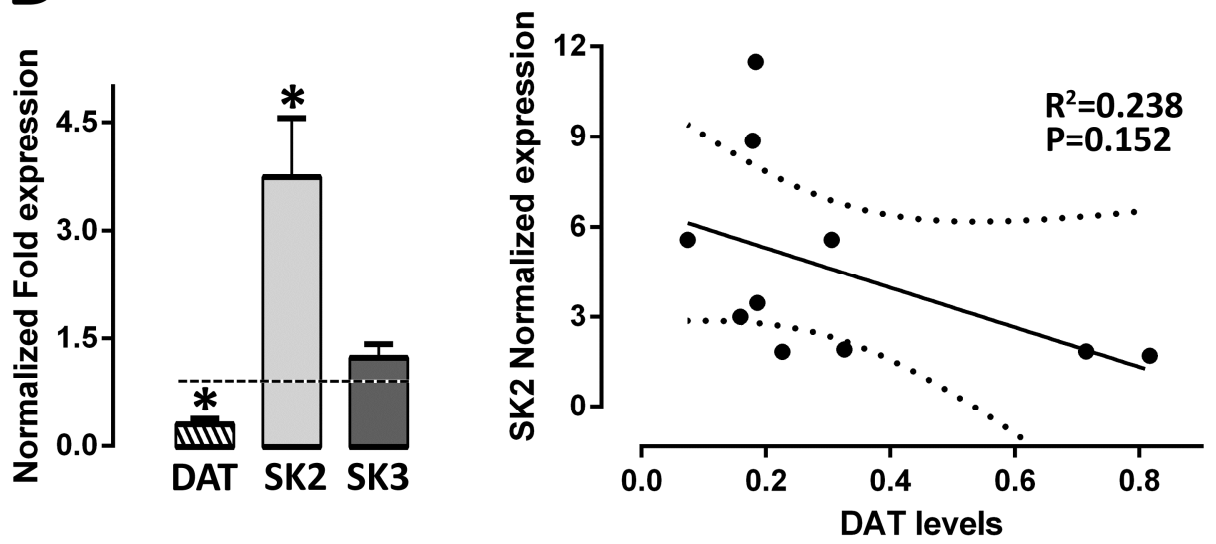
B Subthalamic nucleus

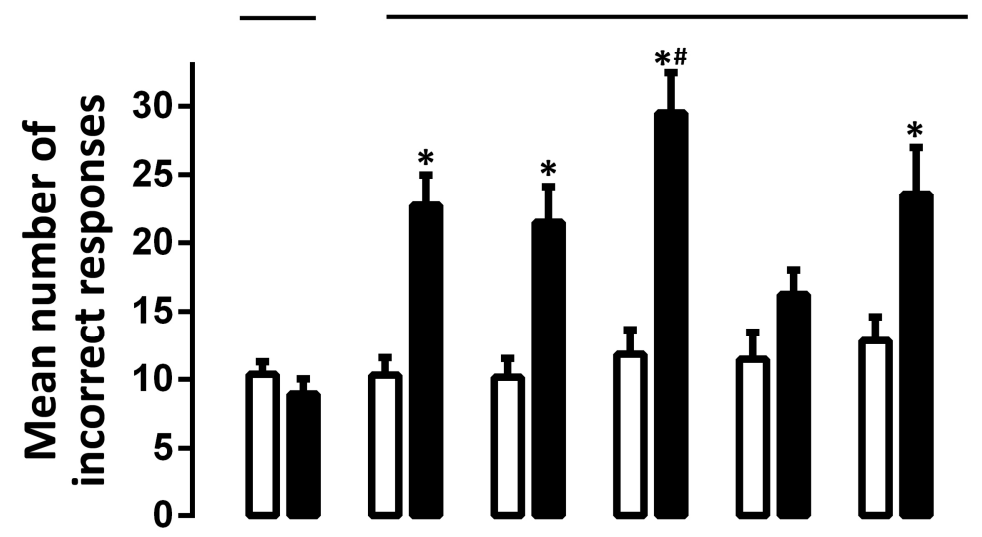

$\mathrm{NaCl}$

Apamin $0.1 \mathrm{ng}$ CyPPA $1 \mu \mathrm{g}$

A Substantia nigra

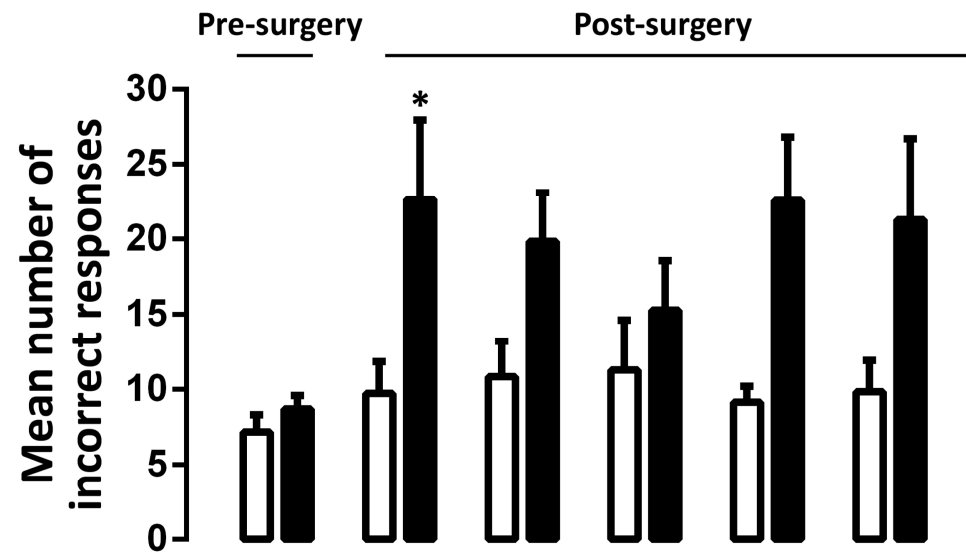

$\mathrm{NaCl}$

Apamin $0.2 \mathrm{ng}$

CyPPA $1 \mu \mathrm{g}$ 